\title{
Allosteric modulation of Protein Arginine Methyltransferase 5 (PRMT5)
}

\author{
Rachel L. Palte*†, Sebastian E. Schneider*†, Michael D. Altman ${ }^{\dagger}$, Robert P. Hayes ${ }^{\S}$, \\ Shuhei Kawamura`, Brian M. Lacey ${ }^{\varnothing}$, My Sam Mansueto ${ }^{\varnothing}$, Michael Reutershan', Phieng

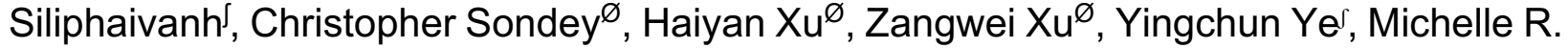 \\ Machacek \\ † Computational and Structural Chemistry, $\int$ Discovery Chemistry, $\varnothing$ Quantitative Biosciences, Merck \& \\ Co., Inc., 33 Avenue Louis Pasteur, Boston, Massachusetts, 02115, United States § Computational and \\ Structural Chemistry, West Point, Pennsylvania, 19486, United States
}

\section{Table of contents}

Expression and Purification of PRMT5/MEP50 Complex for Biochemical Assay 2

PRMT5-MEP50 Enzyme Methylation Assay (Fig S1 on page 4) 3

PRMT5 Cell Target Engagement (TE) Assay (Fig S2 on page 5) 4

Surface Plasmon Resonance Binding Experiments (Fig S3 on page 7) 6

$\begin{array}{ll}\text { Chemistry General Materials and Methods } & 8\end{array}$

Synthetic Procedures for Representative Compounds $\quad 9$

Cloning, Expression, and Purification of Protein for Crystallography 25

$\begin{array}{ll}\text { Crystallization and Structural Analysis } & 26\end{array}$

Crystal Data Collection and Refinement Statistics Table (Table S1) 27

PRMT Loop Overlay, Sequence Comparison, and C $\alpha$ RMSD values (Figs S4, S5, Table S2) 28

Overlay of PRMT3 and PRMT5 crystal structures (Fig S6) 29

Binding site of the allosteric PRMT3 compound (Fig S7) 29

Synthetic Procedures and Characterization Data for Mosher Amides of Compound 1a 30

Corrected Mean Average Error for DFT Chemical Shifts (Table S3) 31 


\section{Expression and Purification of PRMT5/MEP50 Complex for Biochemical Assay}

Avi-tagged PRMT5 (2-637) and His-tagged MEP50 (2-342) were individually cloned into pBAC1 vectors for co-expression in $s f 21$ cells. $10 \mathrm{~L}$ of $2.8 \times 10^{\wedge} 6$ cells $/ \mathrm{mL}$ were coinfected with P2 BIICs (Baculovirus Infected Insect Cells) at $0.2 \mathrm{MOI}$ in a $20 \mathrm{~L}$ wave bag, rocking at $28 \mathrm{rpm}$ for $72 \mathrm{hrs}$ post infection. Cells were pelleted at $3,400 \mathrm{x} \mathrm{g}$ for $10 \mathrm{~min}$ and frozen at $-80^{\circ} \mathrm{C}$ until date of purification. 1.5 L of Lysis buffer (50 mM HEPES pH 7.3, $300 \mathrm{~mL} \mathrm{NaCl}, 1 \mathrm{mM}$ DTT, $20 \mathrm{mM}$ Imidazole, 5\% Glycerol, 1 tablet/ $50 \mathrm{~mL}$ Protease Inhibitor Tablets w/o EDTA and 50 units $/ \mathrm{mL}$ Benzonase) was added to cell pellet and homogenized with a dounce homogenizer. Lysate was further homogenized with a microfluidizer ( 2 cycles at $17 \mathrm{kPsi}$ ). The resulting lysate was spun for 120 mins at 45,000 g and clarified lysate was loaded onto a $5 \mathrm{~mL}$ HisTrap FF Crude column using an AKTA System. Protein was eluted over a gradient with $50 \mathrm{mM}$ HEPES pH 7.3, $300 \mathrm{mM} \mathrm{NaCl}$, 20-300 mM Imidazole, 5\% Glycerol and $1 \mathrm{mM}$ DTT. Fractions containing PRMT5/MEP50 proteins were pooled and biotinylated with BirA (8:1 protein to BirA molar ratio) during dialysis into SEC buffer $\left(18 \mathrm{hrs}\right.$ at $\left.4^{\circ} \mathrm{C}\right)$. Greater than $90 \%$ biotinylation was observed by streptavidin gel shift assay. The biotinylated complex was further purified over a Superdex 200 26/60 column in SEC buffer (50 mM HEPES pH 7.3, $200 \mathrm{mM} \mathrm{NaCl}, 10 \%$ Glycerol and $5 \mathrm{mM}$ DTT). It should be noted that PRMT5 and MEP50 coelute as a complex throughout the purification and eluted as a mono-dispersed symmetrical peak on the Superdex 200 column. Final PRMT5-MEP50 complex was $>70 \%$ pure and was concentrated and flash frozen. 


\section{PRMT5-MEP50 Enzyme Methylation Assay}

PRMT5-MEP50 biochemical assay is a direct measurement of the methylation activity of the enzyme complex on a short peptide substrate derived from the $\mathrm{N}$-terminus of $\mathrm{H} 4$ histone. Methylation experiment is performed with recombinant PRMT5-MEP50 protein complex. The assessment of inhibitory effect of small molecules is measured by the effectiveness of the compounds to inhibit this reaction $\left(\mathrm{EC}_{50}\right)$. In this assay, the potency $\left(\mathrm{EC}_{50}\right)$ of each compound was determined from a twenty-point (1:2 serial dilution; top compound concentration of $100000 \mathrm{nM}$ ) titration curve using the following outlined procedure. To each well of a white ProxiPlus 384 wellplate, $100 \mathrm{~nL}$ of compound (1\% DMSO in final assay volume of $10 \mu \mathrm{L})$ was dispensed, followed by the addition of $8 \mu \mathrm{L}$ of $1 \mathrm{x}$ assay buffer (50 mM Bicine $\mathrm{pH} 8.0,1 \mathrm{mM}$ DTT, 0.004\% Tween20, $0.01 \%$ BSA) containing $1.25 \mathrm{nM}$ of Full-length (FL)-PRMT5-MEP50 enzyme complex (recombinant proteins from baculovirus-transfected Sf21 cells: FL-PRMT5; MW = 73837 kDa and FL-MEP50; MW $=38614)$ and $1 \mu \mathrm{L}$ of $150 \mu \mathrm{M} \mathrm{S}$-(5'-Adenosyl)-L-Methionine Chloride (SAM). Plates were sealed and placed in a $37^{\circ} \mathrm{C}$ humidified chamber for a 60 minutes preincubation with compound. Subsequently, each reaction was initiated by the addition of $1 \mu \mathrm{L} 1 \mathrm{x}$ assay buffer containing $750 \mathrm{nM}$ biotinylated H4R3(Me1) peptide. The final reaction in each well of $10 \mu \mathrm{L}$ consists of $1.0 \mathrm{nM}$ PRMT5-MEP50, $75 \mathrm{nM}$ biotinylated-peptide, and $15 \mu \mathrm{M}$ SAM. Methylation reactions were allowed to proceed for 150 minutes in a sealed plate at $37^{\circ} \mathrm{C}$. Reactions were immediately quenched by the addition of $1 \mu \mathrm{L}$ of $5 \%$ formic acid. Plates were then frozen and shipped to SAMDITM Tech Inc. to determine the percent conversion from H4R3(Me1) to H4R3(Me2). Dose-response curves were generated by plotting percent effect (\% product conversion; Y-axis) vs. $\log 10$ compound concentrations (X-axis). $\mathrm{EC}_{50}$ values were determined by non-linear regression according to model for sigmoidal (4 parameters) dose-response curves. 

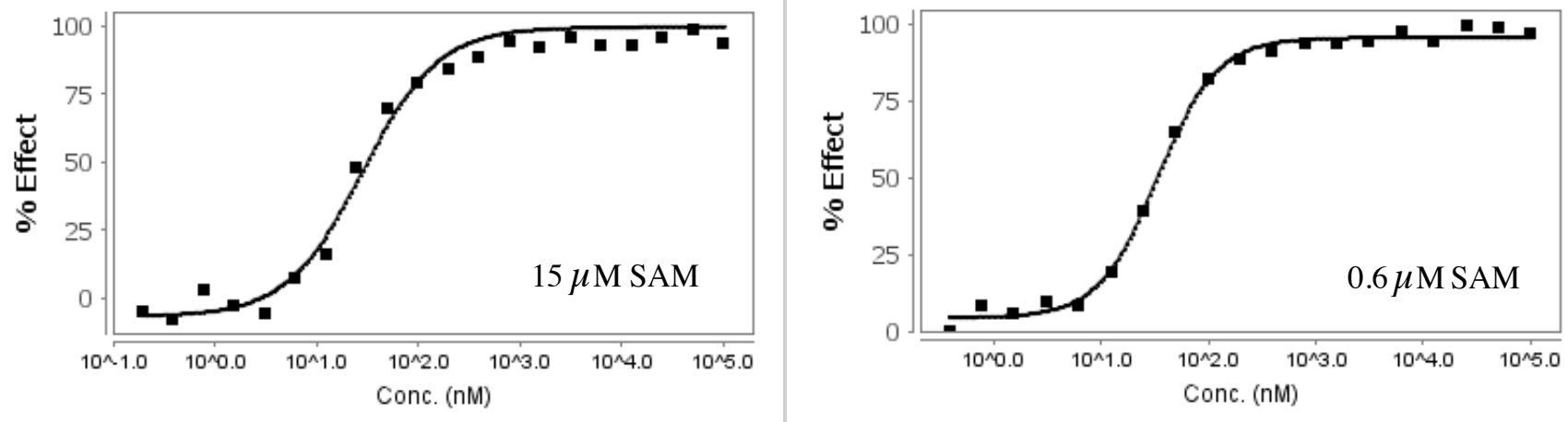

Fig S1. Percent inhibition calculated from biochemical PRMT5:MEP50 methylation assay with Compound 1a. Response curves from the biochemical enzyme methylation assay with Compound 1a with SAM at $\sim \mathrm{K}_{\mathrm{M}}$ and $25 \mathrm{x} \mathrm{K}_{\mathrm{M}}$.

\section{PRMT5 Cell Target Engagement (TE) Assay}

The PRMT5 TE assay is a biomarker assay for identifying compounds that inhibit symmetric dimethylation of arginine (SDMA) of PRMT5 substrates. Specifically, symmetrically dimethylated nuclear proteins are detected using high content imaging technology. Detection of the expression of symmetrically dimethylated nuclear proteins is through a mixture of primary rabbit monoclonal antibodies to SDMA (CST 13222), which in turn recognized by an Alexafluor 488 dye-conjugated anti-rabbit IgG secondary antibody. The IN Cell Analyzer 2200 or OperaPhenix measures nuclear Alexafluor 488 fluorescent dye intensity that is directly related to the level of expression of symmetrically dimethylated nuclear proteins at the single cell level. Nuclear AF488 dye intensities are compared to the mean value for DMSO treated cells (MIN) to report percent of inhibition for each compound-treated well.

In this assay, the cell potency $\left(\mathrm{EC}_{50}\right)$ of each compound was determined from a ten point (1:3 serial dilution; top compound concentration of $10000 \mathrm{nM}$ ) titration curve using the following outlined procedure. Each well of a BD falcon collagen coated black/clear bottom 384-well plate was seeded with 4000 MCF-7 cells in 30ul media and allowed to attach for 5 hours. Media is ATCC-formulated Eagle's Minimum Essential Medium, Catalog No. 30-2003. To make the complete growth medium, the following components were added to the base medium: $0.01 \mathrm{mg} / \mathrm{ml}$ human recombinant insulin; fetal bovine serum to a final concentration of $10 \%$. Additional $30 \mathrm{ul}$ of media containing $2 \mathrm{x}$ compounds were added to each well. Cells were treated for 3 days in $37^{\circ} \mathrm{C}$ $5 \% \mathrm{CO}_{2}$ incubator. On day 3 , cells were fixed with Cytofix, permeablized with $0.4 \%$ Triton-X- 
100/Cytofix, and washed with D-PBS without Ca/Mg. Cells were blocked with Licor Odessey blocking reagent for $1 \mathrm{hr}$ at room temperature, followed by incubation with anti-SDMA (1:1000) antibody at $4^{\circ} \mathrm{C}$ overnight. $1^{\circ}$ antibody was removed, followed by three washings with DPBS without $\mathrm{Ca} / \mathrm{Mg}$ and $0.05 \%$ Tween20. Hoechst $(5 \mathrm{mg} / \mathrm{ml})$, Cell Mask deep red stain (1:2000) and Alexa488-conjugated goat anti-rabbit $\operatorname{IgG}(2 \mu \mathrm{g} / \mathrm{mL})$ was added for 1 hour at room temperature. A final washing step (three washes) was performed before sealing plate for imaging on In Cell Analyzer 2200 or Opera-Phenix. Images from analyzer were uploaded to Columbus (at WP or BOS) for image analysis. $\mathrm{IC}_{50}$ values were determined by 4 parameters robust fit of percent fluorescence units vs. $\left(\log _{10}\right)$ compound concentrations.
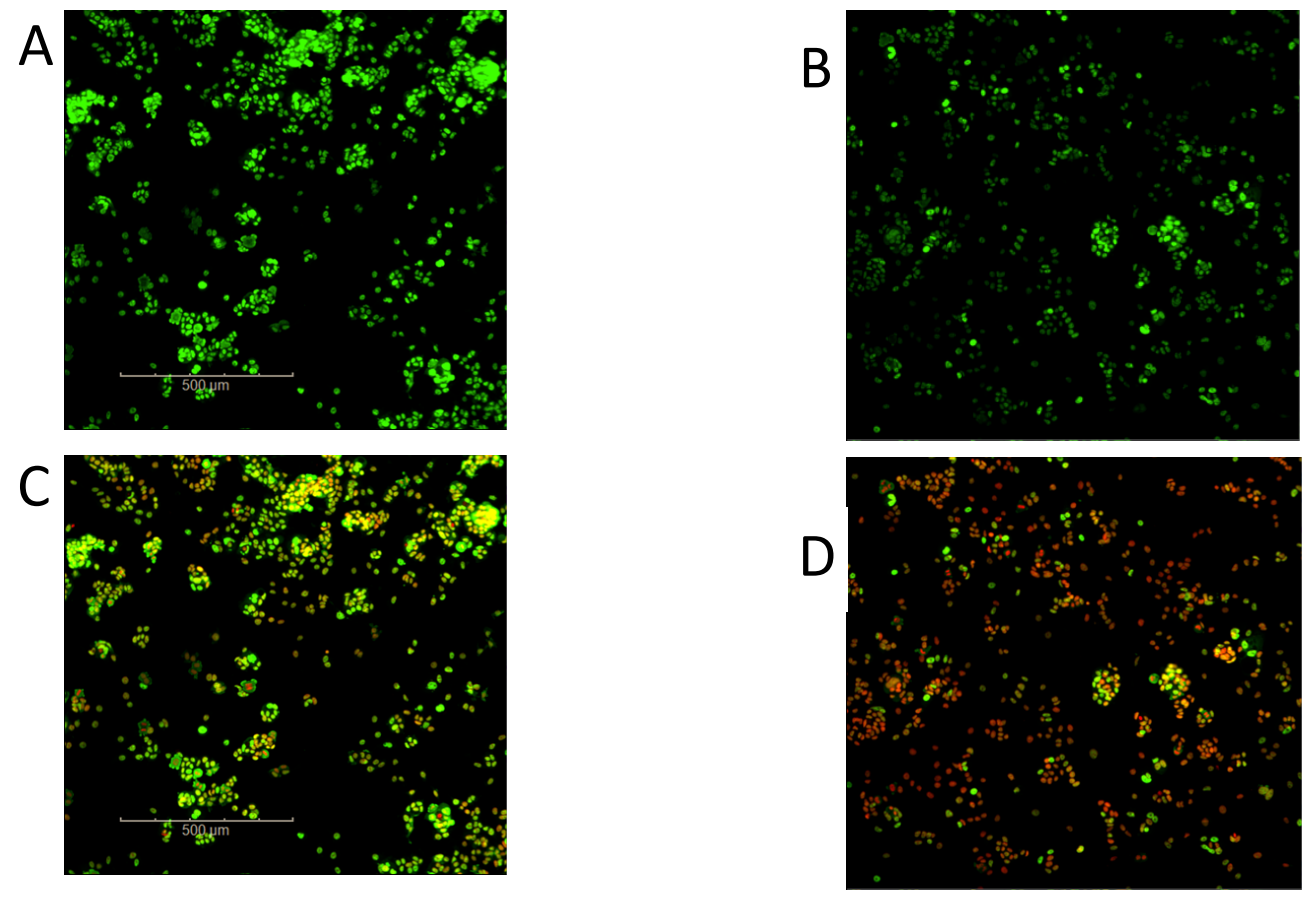

Figure S2. Expression of nuclear SDMA detected by high content imaging using SDMA antibody. MCF-7 cells were treated either with DMSO (A) or 10uM L-3934 (B). Secondary antibody was labeled with Alexa Fluor 488 dye (AF488) which is seen here as green fluorescence. These same cells were also stained with DAPI stain to show the presence of all nuclei. Images (C) and (D) are superimposed images the AF488-labeled cells (A) and (B), respectively, with the DAPI-stained cells, and the DAPI stain was given an artificial red color to more easily show the presence of all nuclei. 


\section{Surface Plasmon Resonance Binding Experiments}

The Biacore T200 instrument was used to carry out surface plasmon resonance binding experiments. A biotinylated Human PRMT5:MEP50 complex was prepared in immobilization buffer (HBS-P+, GE Healthcare, supplemented with $5 \mathrm{mM}$ dithiothreitol) and the ligand was flowed onto a Biacore Series S Sensor Chip SA, (following the manufacturer's general recommended conditions) to a final capture level of $~ 3500$ RU onto channels 2-4. The sensor chip was then equilibrated in running buffer (immobilization buffer containing $3 \% \mathrm{v} / \mathrm{v}$ dimethyl sulfoxide) and compound binding experiments were carried out in this buffer. The compound interaction with PRMT5:MEP50 complex was tested on each channel $(n=3)$ using a 5-point, 3fold dilution series $(0.123-10 \mathrm{uM})$ followed by a single dissociation step using single cycle kinetics mode (contact and dissociation times of 230 and $1800 \mathrm{sec}$, respectively). Resulting sensorgrams were solvent corrected and double reference subtracted (blank injection with reference flow cell). Conditions were repeated on a fresh Biacore Series S Sensor Chip SA in which $15 \mu \mathrm{M}$ S-(5'Adenosyl)-L-methionine (SAM) Chloride (American Radioligand Chemicals, Inc.) was included in the running buffer. The Biacore Evaluation software was used to fit the data to a 1:1 binding model. 


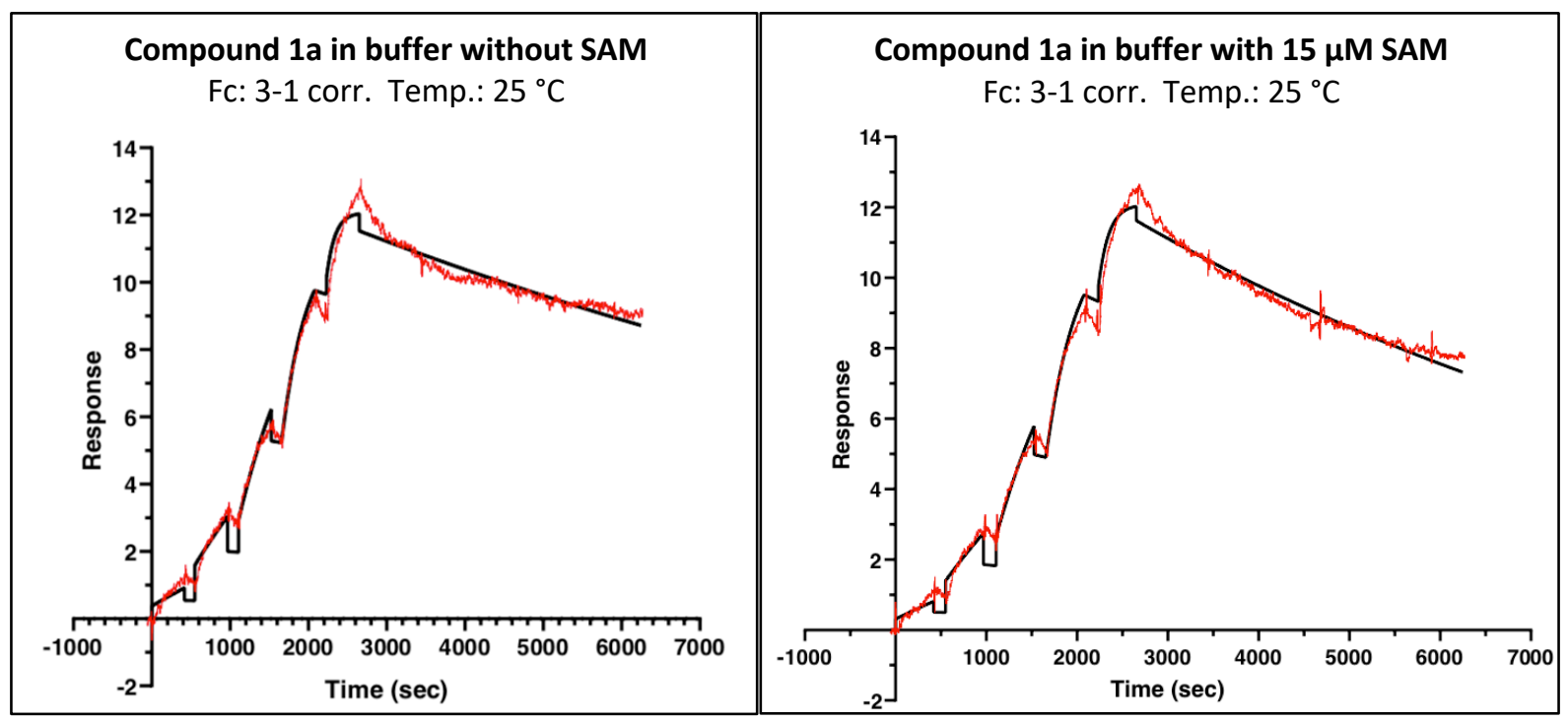

\begin{tabular}{|rc|}
\hline Injection & Compound (nM) \\
Conc. 1 & 123.456 \\
Conc. 2 & 370.370 \\
Conc. 3 & 1111.111 \\
Conc. 4 & 3333.333 \\
Conc. 5 & 10000.000 \\
\hline
\end{tabular}

\begin{tabular}{|c|c|c|c|c|c|}
\hline compound & [SAM] & $\boldsymbol{k}_{\mathrm{a}}(\mathbf{1} / \mathbf{M s})$ & $\boldsymbol{k}_{\mathrm{d}}(\mathbf{1} / \mathbf{s})$ & $\boldsymbol{K}_{\mathrm{D}}(\mathbf{M})$ & $\boldsymbol{K}_{\mathrm{D}}$ Fold change \\
\hline $1 \mathrm{a}$ & $0 \mu \mathrm{M}$ & 930.5 & $7.8 \times 10^{-5}$ & $8.3 \times 10^{-8}$ & 1 \\
\hline $1 \mathrm{a}$ & $15 \mu \mathrm{M}$ & 860.4 & $12.9 \times 10^{-5}$ & $15.0 \times 10^{-8}$ & 1.8 \\
\hline
\end{tabular}

Figure S3. Single cycle kinetic SPR data for Compound 1a with and without SAM. Raw SPR data (red) is shown here with a 1:1 binding model overlaid (black). The concentration of compound 1a used at each injection are listed in the first table. The association rate constant $\left(k_{\mathrm{a}}\right)$, dissociation rate constant $\left(k_{\mathrm{d}}\right)$ and overall equilibrium dissociation constant $\left(K_{\mathrm{D}}\right)$ are shown in the table. The $K_{\mathrm{D}}$ values both in the presence and absence of SAM are within twofold, highlighting that the presence of SAM does not change the binding of Compound 1a. It should be noted that the 1:1 model does not optimally fit the experimental data and therefore these reported values are relative kinetic parameters. 


\section{Chemistry General Materials and Methods}

All reagents and solvents were purchased from commercial sources and used as is without further purification. Reaction progress and synthetic intermediate analysis was assessed by LCMS (UV detection with ESI mass detection) when applicable using an Agilent or Shimadzu instrument with a MeCN/water gradient with either TFA or $\mathrm{NH}_{4} \mathrm{OH}$ modifier. All reported yields are isolated yields. Silica gel and reverse-phase flash column chromatography were conducted with Teledyne ISCO CombiFlash or Biotage-Isolera One instruments and commercially available pre-packed columns. Reverse-phase preparative HPLC purification of final analogs was performed on a Gilson preparative HPLC instrument with UV detection using a MeCN/water gradient with either TFA or $\mathrm{NH}_{4} \mathrm{OH}$ modifier. Chiral SFC separation was performed on Thar200 preparative SFC(SFC-10), Sepiatec Prep 100 or SFC80Q with solvent and modifier noted in the experimental. All reported compounds tested in the assays were $\geq 95 \%$ pure as determined by LCMS or HPLC analysis. ${ }^{1} \mathrm{H}$ NMR spectra were collected at room temperature. Chemical shifts are reported in ppm relative to the listed deuterated solvent, and multiplicities, coupling constants (where applicable), and signal integrations are listed parenthetically. Final compounds were isolated either as the TFA salts or the free base after purification. Safety statement: given the highly potent nature of the final compounds whose preparation is detailed in this section, and their demonstrated ability to inhibit PRMT5 in vitro and in vivo, proper procedures for the handling of these highly potent compounds should be followed at all times in accordance with institutional policies. 


\section{Synthetic procedures for representative compounds}

Compound 1a: (5R)-5-(adamantan-1-yl)-2-amino-5-(4-methoxyphenyl)-3-methyl-3,5dihydro-4H-imidazol-4-one and Compound 1b: (5S)-5-(adamantan-1-yl)-2-amino-5-(4methoxyphenyl)-3-methyl-3,5-dihydro-4H-imidazol-4-one<smiles>COc1ccc([C@]2(C34CC5CC(CC(C5)C3)C4)N=C(N)N(C)C2=O)cc1</smiles><smiles>COc1ccc([C@]2(C34CC5CC(CC(C5)C3)C4)N=C(N)N(C)C2=O)cc1</smiles>
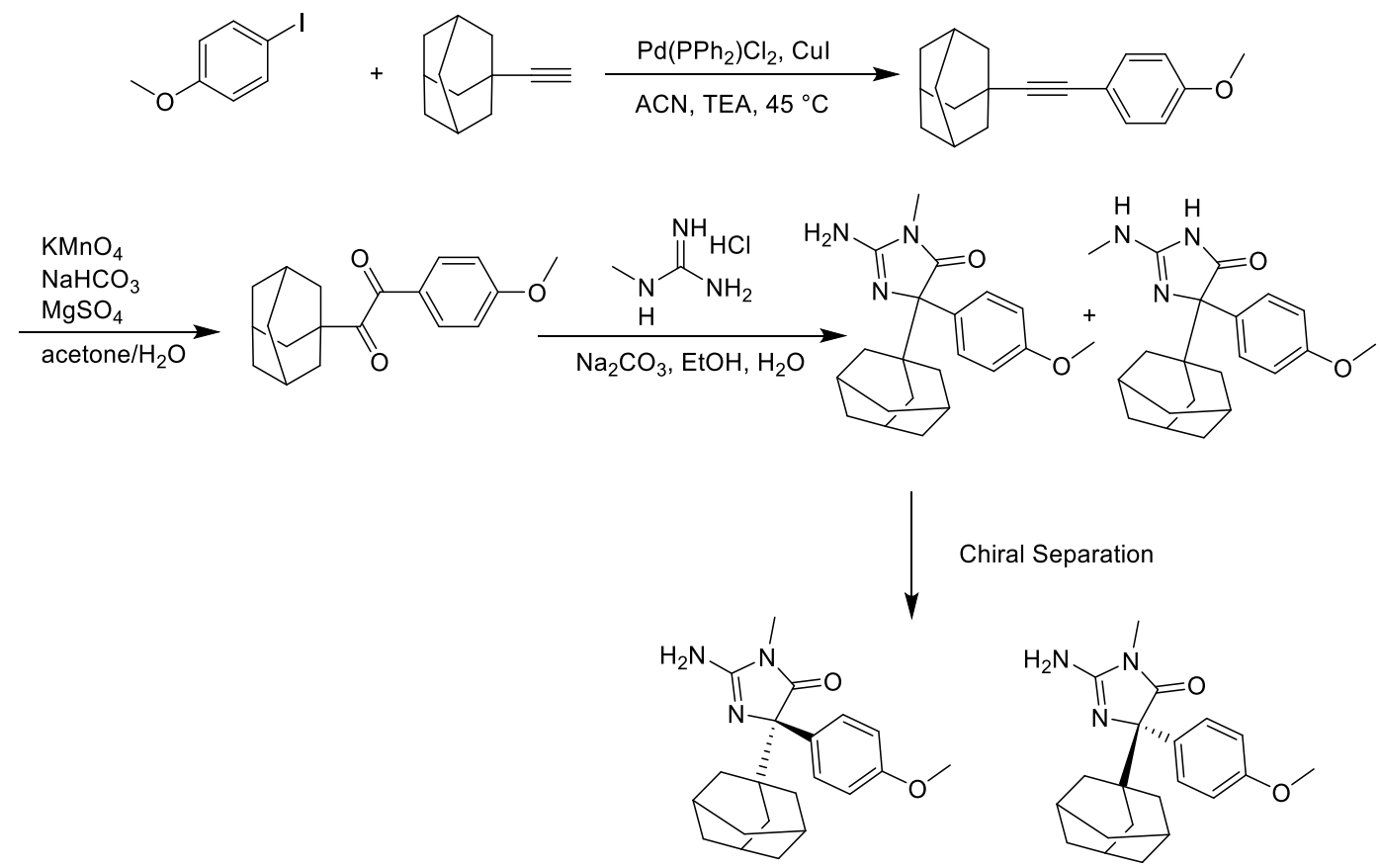

Step 1: A mixture of 1-ethynyladamantane ( $250 \mathrm{mg}, 1.56 \mathrm{mmol})$, 1-iodo-4-methoxybenzene (365 $\mathrm{mg}, 1.56 \mathrm{mmol}$ ), $\mathrm{Pd}\left(\mathrm{PPh}_{3}\right)_{2} \mathrm{Cl}_{2}$ (44 mg, $0.06 \mathrm{mmol}$ ), copper(I) iodide (14.9 mg, $\left.0.08 \mathrm{mmol}\right)$ and $\mathrm{Et}_{3} \mathrm{~N}$ (3 ml, $21.5 \mathrm{mmol}$ ) in acetonitrile ( $3 \mathrm{ml}$ ) was degassed and backfilled with $\mathrm{N}_{2}$ (three times). The mixture was stirred at $45{ }^{\circ} \mathrm{C}$ for $3 \mathrm{~h}$. The mixture was cooled to room temperature and concentrated in vacuo. The residue was purified by column chromatography on silica gel (Pet. ether) to provide 1-((4-methoxyphenyl)ethynyl)adamantane (350 mg, $1.25 \mathrm{mmol}, 80 \%$ yield) as 
colorless oil. ${ }^{1} \mathrm{H}$ NMR (400 MHz, $\left.\mathrm{CDCl}_{3}\right) \delta$ 7.29-7.35 (m, 2H), 6.76-6.82 (m, 2H), $3.79(\mathrm{~s}, 3 \mathrm{H})$, 1.93-2.01 (m, 9H), 1.71 (br s, 6H).

Step 2: To a mixture 1-((4-methoxyphenyl)ethynyl)adamantane (2.2 g, $8.26 \mathrm{mmol})$ in acetone (30 $\mathrm{mL}$ ) was added a solution of $\mathrm{NaHCO}_{3}(0.41 \mathrm{~g}, 4.96 \mathrm{mmol})$ and $\mathrm{MgSO}_{4}(1.49 \mathrm{~g}, 12.39 \mathrm{mmol})$ in $\mathrm{H}_{2} \mathrm{O}(15 \mathrm{~mL}) . \mathrm{KMnO}_{4}(3.92 \mathrm{~g}, 24.78 \mathrm{mmol})$ was then added in one portion. The resulting mixture was stirred at $30^{\circ} \mathrm{C}$ for $16 \mathrm{~h}$. Water $(60 \mathrm{~mL})$ was added and the mixture was extracted with EtOAc $(30 \mathrm{~mL} \times 3)$. The combined organic layers were washed with brine $(30 \mathrm{~mL})$, dried over $\mathrm{Na}_{2} \mathrm{SO}_{4}$, filtered, and the filtrate was concentrated in vacuo. The residue was purified by flash silica gel chromatography (eluting with 8\% ethyl acetate/petroleum ether) to give 1-(adamantan-1-yl)-2-(4methoxyphenyl)ethane-1,2-dione (2.0 g, 73\% yield) as a light yellow solid. ${ }^{1} \mathrm{H}$ NMR (400 MHz, $\left.\mathrm{CDCl}_{3}\right) \delta 7.75-7.79(\mathrm{~m}, 2 \mathrm{H}), 6.96(\mathrm{~d}, J=8.77 \mathrm{~Hz}, 2 \mathrm{H}), 3.88(\mathrm{~s}, 3 \mathrm{H}), 2.04(\mathrm{~s}, 3 \mathrm{H}), 1.94-1.97(\mathrm{~m}$, $6 \mathrm{H}), 1.68-1.77(\mathrm{~m}, 6 \mathrm{H})$

Step 3: A mixture of 1-(adamantan-1-yl)-2-(4-methoxyphenyl)ethane-1,2-dione (100 mg, 0.34 $\mathrm{mmol})$ and 1-methylguanidine hydrochloride (184 mg, $1.68 \mathrm{mmol})$ in 1,4-Dioxane (1 mL) and ethanol $(1 \mathrm{~mL})$ was stirred at $15^{\circ} \mathrm{C}$ for $5 \mathrm{~min}$, and then treated with an aqueous solution of sodium carbonate $(178 \mathrm{mg}, 1.68 \mathrm{mmol})$ in water $(1.0 \mathrm{~mL})$. The mixture was heated at $85^{\circ} \mathrm{C}$ with stirring for $3 \mathrm{~h}$. The mixture was cooled to room temperature and concentrated in vacuo. The residue was purified by Prep-HPLC (YMC-Actus Pro C18 150*30 5u column, water (0.1\%TFA)-MeCN $(25 \% \mathrm{~B}-55 \% \mathrm{~B})$ to give 4-(adamantan-1-yl)-2-amino-4-(4-methoxyphenyl)-1-methyl-1Himidazol-5(4H)-one (63.5 mg, $0.17 \mathrm{mmol}, 51 \%$ yield) as white solid. (LCMS, ESI+) m/z Calcd for $\left[\left(\mathrm{C}_{21} \mathrm{H}_{27} \mathrm{~N}_{3} \mathrm{O}_{2}\right)+\mathrm{H}\right]^{+}:$354, found, 354. ${ }^{1} \mathrm{H} \mathrm{NMR}\left(400 \mathrm{MHz}, \mathrm{CD}_{3} \mathrm{OD}\right) \delta=7.50(\mathrm{~d}, J=8.8 \mathrm{~Hz}, 2 \mathrm{H})$, $6.95(\mathrm{~d}, J=9.2 \mathrm{~Hz}, 2 \mathrm{H}), 3.80(\mathrm{~s}, 3 \mathrm{H}), 3.17$ (s, 3H), 1.99 (br s, 3H), 1.81 (br d, $J=11.8 \mathrm{~Hz}, 3 \mathrm{H})$, $1.73-1.65(\mathrm{~m}, 3 \mathrm{H}), 1.55$ (br d, $J=11.8 \mathrm{~Hz}, 3 \mathrm{H}), 1.47$ (br d, $J=11.8 \mathrm{~Hz}, 3 \mathrm{H})$.

4-(adamantan-1-yl)-2-amino-4-(4-methoxyphenyl)-1-methyl-1H-imidazol-5(4H)-one was separated by chiral SFC (IC, $21 \times 250 \mathrm{~mm}$ column, methanol $+0.25 \%$ dimethyl ethyl amine as modifier, $30 \%$ modifier in $\left.\mathrm{CO}_{2}\right)$ to afford (5S)-5-(adamantan-1-yl)-2-amino-5-(4methoxyphenyl)-3-methyl-3,5-dihydro-4H-imidazol-4-one (peak 1, Compound 1b) and (5R)-5- 
(adamantan-1-yl)-2-amino-5-(4-methoxyphenyl)-3-methyl-3,5-dihydro-4H-imidazol-4-one (peak 2, Compound 1a).

Compound 1a: $[\alpha]_{D}^{25}=+14.9^{\circ}$ (methanol, c 1). (HRMS, ESI+) m/z Calcd. for $\left[\left(\mathrm{C}_{21} \mathrm{H}_{27} \mathrm{~N}_{3} \mathrm{O}_{2}\right)+\mathrm{H}\right]^{+}$: 354.2181, found 354.2182. ${ }^{1} \mathrm{HNMR}$ : $\left(400 \mathrm{MHz}, \mathrm{CDCl}_{3}\right) \delta$ : 7.59-7.64 (m, 2H), 6.82-6.87 (m, 2H), $5.31(\mathrm{~s}, 1 \mathrm{H}), 3.80(\mathrm{~s}, 3 \mathrm{H}), 3.01(\mathrm{~s}, 3 \mathrm{H}), 1.95(\mathrm{bs}, 3 \mathrm{H}), 1.82(\mathrm{bd}, J=11.6 \mathrm{~Hz}, 3 \mathrm{H}), 1.43-1.65(\mathrm{~m}$, $10 \mathrm{H})$.

\section{Compound 1b:}

(LCMS, ESI+) m/z Calcd. for $\left[\left(\mathrm{C}_{21} \mathrm{H}_{27} \mathrm{~N}_{3} \mathrm{O}_{2}\right)+\mathrm{H}\right]^{+}:$354, found 354. ${ }^{1} \mathrm{HNMR}$ : $\left(400 \mathrm{MHz}, \mathrm{CDCl}_{3}\right)$ $\delta: 7.59-7.64(\mathrm{~m}, 2 \mathrm{H}), 6.82-6.87(\mathrm{~m}, 2 \mathrm{H}), 5.31(\mathrm{~s}, 1 \mathrm{H}), 3.80(\mathrm{~s}, 3 \mathrm{H}), 3.01(\mathrm{~s}, 3 \mathrm{H}), 1.95(\mathrm{~s}, 3 \mathrm{H}), 1.82$ (bd, $J=10.8 \mathrm{~Hz}, 3 \mathrm{H}), 1.43-1.65(\mathrm{~m}, 10 \mathrm{H})$.

Compound 2: (5R)-5-(adamantan-1-yl)-2-amino-5-(3-methoxyphenyl)-3-methyl-3,5dihydro-4H-imidazol-4-one

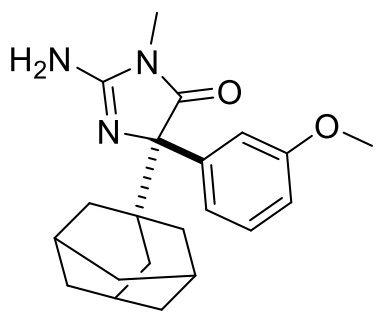

5-(adamantan-1-yl)-2-amino-5-(3-methoxyphenyl)-3-methyl-3,5-dihydro-4H-imidazol-4-one (58.9 $\mathrm{mg}, 0.162 \mathrm{mmol}, 19 \%$ yield) was prepared in analogy to the procedures described for Compound 1a/1b, starting with 1-iodo-3-methoxybenzene and 1-ethynyladamantane. The racemic material was separated by chiral SFC (IC, $21 \times 250 \mathrm{~mm}$ column, methanol $+0.25 \%$ dimethyl ethyl amine as modifier, 30\% modifier in $\left.\mathrm{CO}_{2}\right)$ to afford (5S)-5-(adamantan-1-yl)-2-amino-5-(3methoxyphenyl)-3-methyl-3,5-dihydro-4H-imidazol-4-one (peak 1) and (5R)-5-(adamantan-1yl)-2-amino-5-(3-methoxyphenyl)-3-methyl-3,5-dihydro-4H-imidazol-4-one (peak 2, Compound 2).

Compound 2: (HRMS, ESI+) m/z Calcd for $\left[\left(\mathrm{C}_{21} \mathrm{H}_{27} \mathrm{~N}_{3} \mathrm{O}_{2}\right)+\mathrm{H}\right]^{+}, 354.2181$, found, 354.2177. ${ }^{1} \mathrm{H}$ NMR (400 MHz, DMSO-d $) \delta 7.29-7.23(\mathrm{~m}, 2 \mathrm{H}), 7.17$ (t, $J=7.9 \mathrm{~Hz}, 1 \mathrm{H}), 6.79$ (d, $J=8.1 \mathrm{~Hz}$, 
1H), $3.70(\mathrm{~s}, 3 \mathrm{H}), 2.87(\mathrm{~s}, 3 \mathrm{H}), 1.93-1.84(\mathrm{~m}, 5 \mathrm{H}), 1.73-1.64(\mathrm{~m}, 3 \mathrm{H}), 1.60-1.51(\mathrm{~m}, 3 \mathrm{H})$, $1.47-1.35(\mathrm{~m}, 6 \mathrm{H})$.

\section{Compound 3: (5R)-5-(adamantan-1-yl)-2-amino-3-methyl-5-phenyl-3,5-dihydro-4H- imidazol-4-one}

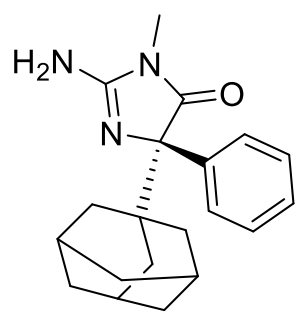

1-(adamantan-1-yl)-2-phenylethane-1,2-dione (706 mg, $2.2 \mathrm{mmol}, 48 \%$ yield) was prepared in analogy to Steps 1 and 2 of the procedures described for Compound $1 \mathrm{a} / 1 \mathrm{~b}$, starting with iodobenzene and 1-ethynyladamantane.

A mixture of 1-(adamantan-1-yl)-2-phenylethane-1,2-dione (200 $\mathrm{mg}, 0.745 \mathrm{mmol})$ and 1methylguanidine hydrochloride $(408 \mathrm{mg}, 3.73 \mathrm{mmol})$ in 1,4-dioxane $(2 \mathrm{ml})$ and ethanol $(2 \mathrm{~mL})$ was stirred at $28^{\circ} \mathrm{C}$ for $5 \mathrm{~min}$. Then, a solution of $\mathrm{Na}_{2} \mathrm{CO}_{3}(395 \mathrm{mg}, 3.73 \mathrm{mmol})$ in water $(2 \mathrm{~mL})$ was added. The reaction was stirred at $85{ }^{\circ} \mathrm{C}$ for $5 \mathrm{~h}$. The resulting mixture was cooled and then concentrated under vacuum. The resulting residue was purified by prep-HPLC (Xtimate C18 $150 * 25 \mathrm{~mm} * 5$ um column, water $\left.\left(10 \mathrm{mM} \mathrm{NH} \mathrm{NCO}_{3}\right): \mathrm{MeCN}, 52 \% \mathrm{~B}-82 \% \mathrm{~B}\right)$ to give 4(adamantan-1-yl)-2-amino-1-methyl-4-phenyl-1H-imidazol-5(4H)-one (73.3 mg, $0.23 \mathrm{mmol}$, $30 \%$ yield). ${ }^{1} \mathrm{H}$ NMR (400 MHz, DMSO-d 6 ) $\delta 7.69$ (d, $J=7.34$ Hz, 2H), 7.17-7.31 (m, 3H), 6.39 (br s, 2H), 2.87 (s, 3H), 1.88 (br s, 3H), 1.70 (br d, $J=11.74 \mathrm{~Hz}, 3 \mathrm{H}), 1.56$ (br d, $J=11.74 \mathrm{~Hz}$, $3 \mathrm{H}$ ), 1.42 (br d, $J=11.25 \mathrm{~Hz}, 6 \mathrm{H}$ ). (LCMS ESI+) m/z Calcd. for $\left[\left(\mathrm{C}_{20} \mathrm{H}_{25} \mathrm{~N}_{3} \mathrm{O}\right)+\mathrm{H}\right]^{+}, 324$, found, 324.

Chiral SFC separation of 4-(adamantan-1-yl)-2-amino-1-methyl-4-phenyl-1H-imidazol-5(4H)one (IC, $21 \times 250 \mathrm{~mm}$ column, methanol $+0.1 \% \mathrm{NH}_{3} \mathrm{H}_{2} \mathrm{O}$ as modifier, $40 \%$ modifier in $\mathrm{CO}_{2}$ ) afforded (5R)-5-(adamantan-1-yl)-2-amino-3-methyl-5-phenyl-3,5-dihydro-4H-imidazol-4-one 
(peak 1, Compound 3) and (5S)-5-(adamantan-1-yl)-2-amino-3-methyl-5-phenyl-3,5-dihydro-4Himidazol-4-one (peak 2).

Compound 3: ${ }^{1} \mathrm{H}$ NMR (400 MHz, DMSO-d 6 ) $\delta 7.67$ (br d, $\left.J=7.45 \mathrm{~Hz}, 2 \mathrm{H}\right), 7.15-7.29$ (m, 3H), 6.38 (br s, 2H), 2.85 (s, 3H), 1.85 (br s, 3H), 1.67 (br d, $J=11.40 \mathrm{~Hz}, 3 \mathrm{H}), 1.53$ (br d, $J=11.84$ $\mathrm{Hz}, 3 \mathrm{H}$ ), 1.39 (br d, $J=11.40 \mathrm{~Hz}, 6 \mathrm{H})$. (HRMS, ESI+) m/z Calcd for. for $\left[\left(\mathrm{C}_{20} \mathrm{H}_{25} \mathrm{~N}_{3} \mathrm{O}\right)+\mathrm{H}\right]^{+}$, 324.2076, found, 324.2081.

Compound 4: (5R)-5-(adamantan-1-yl)-2-amino-3-methyl-5-(naphthalen-2-yl)-3,5-dihydro4H-imidazol-4-one

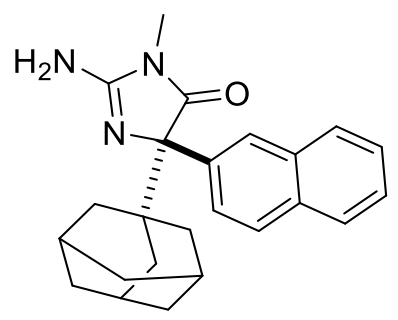

1-(adamantan-1-yl)-2-(naphthalen-2-yl)ethane-1,2-dione (73 mg, $0.19 \mathrm{mmol}, 26 \%$ yield) was prepared in analogy to Steps 1 and 2 of the procedures described for Compound $1 \mathrm{a} / 1 \mathrm{~b}$, starting with 2-iodonaphthalene and 1-ethynyladamantane.

A mixture of 1-(adamantan-1-yl)-2-(naphthalen-2-yl)ethane-1,2-dione (240 mg, $0.754 \mathrm{mmol})$ in dioxane $(2.2 \mathrm{~mL})$ and $\mathrm{EtOH}(2.2 \mathrm{~mL})$ was stirred at $25{ }^{\circ} \mathrm{C}$ for $15 \mathrm{~min}$. 1-Methylguanidine hydrochloride (413 mg, $3.77 \mathrm{mmol}$ ) was added and stirred at $25{ }^{\circ} \mathrm{C}$ for $15 \mathrm{~min}$. A solution of $\mathrm{Na}_{2} \mathrm{CO}_{3}(399.4 \mathrm{mg}, 3.77 \mathrm{mmol})$ in water $(2.2 \mathrm{~mL})$ was added and the mixture was stirred at $85^{\circ} \mathrm{C}$ for $12 \mathrm{~h}$. The solution was cooled and concentrated under vacuum. The residue was purified by Prep-HPLC (Xtimate C18 150*25mm*5um column, water $\left(10 \mathrm{mM} \mathrm{NH}_{4} \mathrm{HCO}_{3}\right)$ : $\mathrm{MeCN}, 60 \% \mathrm{~B}$ 90\%B) to give 4-(adamantan-1-yl)-2-amino-1-methyl-4-(naphthalen-2-yl)-1H-imidazol-5(4H)one (73 mg, $0.19 \mathrm{mmol}, 26 \%$ yield). ${ }^{1} \mathrm{H}$ NMR (400 MHz, d6-acetone) $\delta 8.28$ (s, 1H), 7.99 (dd, $J$ $=1.75,8.77 \mathrm{~Hz}, 1 \mathrm{H}), 7.82-7.89(\mathrm{~m}, 2 \mathrm{H}), 7.78(\mathrm{~d}, J=8.77 \mathrm{~Hz}, 1 \mathrm{H}), 7.43-7.50(\mathrm{~m}, 2 \mathrm{H}), 3.02(\mathrm{~s}$, 3H), 1.83-1.94 (m, 6H), 1.55-1.65 (m, 6H), 1.46-1.53 (m, 3H). Note: Presumably, due to moisture 
in $d 6$-acetone, resonances for the two amino protons were not observed. (LCMS ESI + ) $\mathrm{m} / \mathrm{z}$ Calcd for $\left[\left(\mathrm{C}_{24} \mathrm{H}_{27} \mathrm{~N}_{3} \mathrm{O}\right)+\mathrm{H}\right]^{+}, 374$, found, 374 .

Chiral SFC separation of 4-(adamantan-1-yl)-2-amino-1-methyl-4-(naphthalen-2-yl)-1Himidazol-5(4H)-one $\left(\mathrm{CCOF}_{4}, 21 \times 250\right.$, methanol $0.25 \%$ DMEA as modifier, $20 \%$ modifier in $\mathrm{CO}_{2}$ ) afforded (5R)-5-(adamantan-1-yl)-2-amino-3-methyl-5-(naphthalen-2-yl)-3,5-dihydro-4Himidazol-4-one (peak 1, Compound 4) and (5S)-5-(adamantan-1-yl)-2-amino-3-methyl-5(naphthalen-2-yl)-3,5-dihydro-4H-imidazol-4-one (peak 2).

Compound 4: ' ${ }^{H} \mathrm{H}$ NMR (400 MHz, DMSO- $\left.d_{6}\right) \delta 8.17(\mathrm{~s}, 1 \mathrm{H}), 7.89(\mathrm{~d}, J=8.6 \mathrm{~Hz}, 1 \mathrm{H}), 7.87-$ $7.82(\mathrm{~m}, 2 \mathrm{H}), 7.79(\mathrm{~d}, J=8.7 \mathrm{~Hz}, 1 \mathrm{H}), 7.50-7.43(\mathrm{~m}, 2 \mathrm{H}), 2.90(\mathrm{~s}, 3 \mathrm{H}), 1.93-1.83(\mathrm{~m}, 5 \mathrm{H})$, $1.80-1.71(\mathrm{~m}, 3 \mathrm{H}), 1.59-1.52(\mathrm{~m}, 3 \mathrm{H}), 1.52-1.45(\mathrm{~m}, 3 \mathrm{H}), 1.44-1.38(\mathrm{~m}, 3 \mathrm{H})$. (HRMS, ESI+) $\mathrm{m} / \mathrm{z}$ Calcd. for $\left[\left(\mathrm{C}_{24} \mathrm{H}_{27} \mathrm{~N}_{3} \mathrm{O}\right)+\mathrm{H}\right]^{+}, 374.2232$, found, 374.2232 .

Compound 5: 2-amino-5-(3-fluoro-5-hydroxyadamantan-1-yl)-5-(4-methoxyphenyl)-3methyl-3,5-dihydro-4H-imidazol-4-one

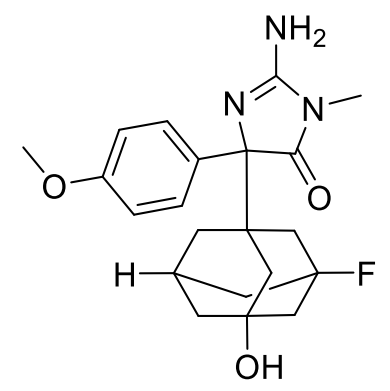

\section{Step 1:}

A mixture of 3-ethynyl-5-fluoroadamantan-1-ol (310 mg, 1.596 mmol), 1-iodo-4-methoxybenzene (374 mg, $1.596 \mathrm{mmol}$ ), $\mathrm{Pd}\left(\mathrm{PPh}_{3}\right)_{2} \mathrm{Cl}_{2}$ (44.8 mg, $0.064 \mathrm{mmol}$ ), copper(I) iodide (15.20 mg, 0.080 mmol) and triethyl amine $(3 \mathrm{ml}, 21.5 \mathrm{mmol})$ in acetonitrile $(3 \mathrm{ml})$ was degassed and backfilled with $\mathrm{N}_{2}$ (three times). The mixture was stirred at $45^{\circ} \mathrm{C}$ for 3 hours and then concentrated under vacuum. The resulting residue was purified by column chromatography on silica gel (petroleum ether/ethyl acetate $=5 / 1$ to $2 / 1)$ to give 3-fluoro-5-((4-methoxyphenyl)ethynyl)adamantan-1-ol (437 mg, $1.31 \mathrm{mmol}, 82 \%$ yield) as a light yellow solid. ${ }^{1} \mathrm{H}$ NMR (400 MHz, $\left.\mathrm{CDCl}_{3}\right) \delta$ 7.29-7.34 
$(\mathrm{m}, 2 \mathrm{H}), 6.81(\mathrm{~d}, J=8.77 \mathrm{~Hz}, 2 \mathrm{H}), 3.80(\mathrm{~s}, 3 \mathrm{H}), 2.42(\mathrm{td}, J=2.96,5.48 \mathrm{~Hz}, 1 \mathrm{H}), 2.03(\mathrm{br} \mathrm{s}, 2 \mathrm{H})$, 1.86-1.94 (m, 4H), 1.81 (br s, 2H), 1.75 (br s, 2H), 1.65 (br s, 2H).

\section{Step 2:}

To a solution of 3-fluoro-5-((4-methoxyphenyl)ethynyl)adamantan-1-ol (437 mg, $1.46 \mathrm{mmol})$ in acetone $(15 \mathrm{ml})$ was added a solution of $\mathrm{MgSO}_{4}(263 \mathrm{mg}, 2.18 \mathrm{mmol})$ and sodium bicarbonate $(73.3 \mathrm{mg}, 0.87 \mathrm{mmol})$ in water $(8 \mathrm{ml})$, followed by the addition of $\mathrm{KMnO}_{4}(690 \mathrm{mg}, 4.36 \mathrm{mmol})$ in one portion. The reaction was stirred for $12 \mathrm{~h}$ at $30{ }^{\circ} \mathrm{C}$. Water $(50 \mathrm{~mL})$ was added and the reaction mixture was extracted with EtOAc $(20 \mathrm{~mL}$ x 3). The combined organic extracts were dried over $\mathrm{MgSO}_{4}$, filtered, and the filtrate was concentrated under vacuum. The residue was purified by column chromatography on silica gel (petroleum ether/ethyl acetate $=2 / 1)$ to give 1-(3-fluoro5-hydroxyadamantan-1-yl)-2-(4-methoxyphenyl)ethane-1,2-dione (390 mg, $1.12 \mathrm{mmol}, 77 \%$ yield) as a light yellow solid. ${ }^{1} \mathrm{H}$ NMR $\left(400 \mathrm{MHz} \mathrm{CDCl}_{3}\right) \delta$ 7.75-7.80 (m, 2H), 6.97 (d, J= 8.77 $\mathrm{Hz}, 2 \mathrm{H}), 3.89(\mathrm{~s}, 3 \mathrm{H}), 2.47-2.54(\mathrm{~m}, 1 \mathrm{H}), 2.03-2.06(\mathrm{~m}, 2 \mathrm{H}), 1.88-1.95(\mathrm{~m}, 4 \mathrm{H}), 1.77-1.85$ (m, $4 \mathrm{H}), 1.67$ (br d, $J=3.95 \mathrm{~Hz}, 2 \mathrm{H})$.

\section{Step 3:}

A mixture of 1-(3-fluoro-5-hydroxyadamantan-1-yl)-2-(4-methoxyphenyl)ethane-1,2-dione (390 $\mathrm{mg}, 1.17 \mathrm{mmol})$ and 1-methylguanidine hydrochloride (643 mg, $5.87 \mathrm{mmol})$ in 1,4-dioxane (2.5 $\mathrm{ml})$ and ethanol $(2.5 \mathrm{~mL})$ was stirred at $25^{\circ} \mathrm{C}$ for $5 \mathrm{~min}$. Then, a solution of $\mathrm{Na}_{2} \mathrm{CO}_{3}(622 \mathrm{mg}, 5.87$ $\mathrm{mmol})$ in water $(2.5 \mathrm{~mL})$ was added. The reaction was stirred at $85^{\circ} \mathrm{C}$ for $5 \mathrm{~h}$. The mixture was then cooled and concentrated under vacuum. The residue was purified by prep-HPLC to give 2amino-4-(3-fluoro-5-hydroxyadamantan-1-yl)-4-(4-methoxyphenyl)-1-methyl-1H-imidazol5(4H)-one (133 mg, $0.34 \mathrm{mmol}, 29 \%$ yield) as a white solid.

Compound 5: ${ }^{1} \mathrm{H}$ NMR (400 MHz, DMSO-d $\left.{ }_{6}\right) \delta 7.59(\mathrm{~d}, J=8.80 \mathrm{~Hz}, 2 \mathrm{H}), 6.86(\mathrm{~d}, J=8.80 \mathrm{~Hz}$, 2H), 6.53 (br s, 2H), 4.75 (s, 1H), 3.73 (s, 3H), 2.89 (s, 3H), 2.22 (br s, 1H), 1.56-1.75 (m, 3H), 1.37-1.55 (m, 6H), 1.12-1.31 (m, 3H). (HRMS, ESI+) m/z Calcd. for $\left[\left(\mathrm{C}_{21} \mathrm{H}_{26} \mathrm{FN}_{3} \mathrm{O}_{3}\right)+\mathrm{H}\right]^{+}$, 388.2036, found, 388.2037. 


\section{Compound 6: (5R)-2-amino-5-(3-hydroxyadamantan-1-yl)-5-(4-methoxyphenyl)-3-methyl-}

\section{3,5-dihydro-4H-imidazol-4-one}

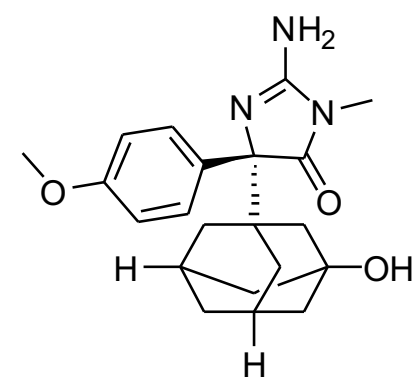

\section{Step 1:}

A mixture of 3-ethynyladamantan-1-ol (160 mg, $0.908 \mathrm{mmol}), 1$-iodo-4-methoxybenzene (212 mg, $0.908 \mathrm{mmol}), \mathrm{Pd}\left(\mathrm{PPh}_{3}\right)_{2} \mathrm{Cl}_{2}(25.5 \mathrm{mg}, 0.036 \mathrm{mmol})$, copper(I) iodide (8.6 mg, $\left.0.05 \mathrm{mmol}\right)$ and triethyl amine $(3 \mathrm{ml}, 21.52 \mathrm{mmol})$ in acetonitrile $(3 \mathrm{ml})$ was degassed and backfilled with $\mathrm{N}_{2}$ (three times), the mixture was stirred at $45^{\circ} \mathrm{C}$ ) for $3 \mathrm{~h}$. The mixture was then cooled to room temperature and concentrated under vacuum. The resulting residue was purified by column chromatography on silica gel (petroleum ether/ethyl acetate $=5 / 1$ to $2 / 1)$ to give 3-((4methoxyphenyl)ethynyl)adamantan-1-ol (210 mg, $0.71 \mathrm{mmol}, 78 \%$ yield) as a light yellow solid.

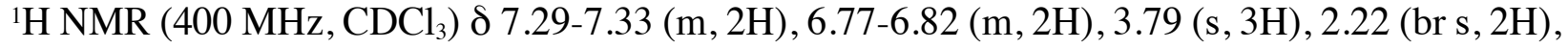
$1.89(\mathrm{~s}, 2 \mathrm{H}), 1.84(\mathrm{~d}, J=1.76 \mathrm{~Hz}, 4 \mathrm{H}), 1.70(\mathrm{~d}, J=2.65 \mathrm{~Hz}, 4 \mathrm{H}), 1.62(\mathrm{~s}, 2 \mathrm{H})$.

\section{Step 2:}

To a solution of 3-((4-methoxyphenyl)ethynyl)adamantan-1-ol (210 $\mathrm{mg}, 0.74 \mathrm{mmol})$ in acetone (15 ml) was added a solution of $\mathrm{MgSO}_{4}(134 \mathrm{mg}, 1.12 \mathrm{mmol})$ and sodium bicarbonate (38 $\mathrm{mg}$, $0.45 \mathrm{mmol})$ in water $(8 \mathrm{ml})$, followed by the addition of $\mathrm{KMnO}_{4}(353 \mathrm{mg}, 2.23 \mathrm{mmol})$ in one portion. The reaction was stirred for $12 \mathrm{~h}$ at $30{ }^{\circ} \mathrm{C}$. Water $(50 \mathrm{~mL})$ was added and the reaction mixture was extracted with ethyl acetate $(20 \mathrm{~mL}$ x 3$)$. The combined organic extracts were dried over $\mathrm{MgSO}_{4}$, filtered, and the filtrate was concentrated under vacuum. The residue was purified by column chromatography on silica gel (petroleum ether/ethyl acetate $=1 / 1)$ to give 1-(3hydroxyadamantan-1-yl)-2-(4-methoxyphenyl)ethane-1,2-dione (150 mg, $0.43 \mathrm{mmol}, 58 \%$ yield) 
as a light yellow solid. ${ }^{1} \mathrm{H} \mathrm{NMR}\left(400 \mathrm{MHz}, \mathrm{CDCl}_{3}\right) \delta$ 7.74-7.79 (m, 2H), $6.96(\mathrm{~d}, J=9.21 \mathrm{~Hz}$, $2 \mathrm{H}), 3.88$ (s, 3H), 2.29 (br s, 2H), 1.80-1.91 (m, 6H), 1.64-1.75 (m, 6H)

\section{Step 3:}

A mixture of 1-(3-hydroxyadamantan-1-yl)-2-(4-methoxyphenyl)ethane-1,2-dione (150 mg, 0.48 $\mathrm{mmol}$ ) and 1-methylguanidine hydrochloride (261 $\mathrm{mg}, 2.39 \mathrm{mmol})$ in 1,4-dioxane (2 $\mathrm{ml})$ and ethanol $(2 \mathrm{~mL})$ was stirred at $30^{\circ} \mathrm{C}$ for $5 \mathrm{~min}$. Then, a solution of $\mathrm{Na}_{2} \mathrm{CO}_{3}(253 \mathrm{mg}, 2.386 \mathrm{mmol})$ in water $(2 \mathrm{~mL})$ was added. The reaction was stirred at $85^{\circ} \mathrm{C}$ for $2 \mathrm{~h}$. The mixture was then cooled to room temperature and concentrated in vacuo. The resulting residue was purified by prep-HPLC (Xtimate $\mathrm{C} 18$ 150*25mm*5um column, water(10mM NH $\mathrm{HCO}_{3}$ ):MeCN, 30\%B-50\%B) to give 2-amino-4-(3-hydroxyadamantan-1-yl)-4-(4-methoxyphenyl)-1-methyl-1H-imidazol-5(4H)-one (85 mg, $0.23 \mathrm{mmol}, 48 \%$ yield) as a white solid. ${ }^{1} \mathrm{H}$ NMR (400 MHz, DMSO-d $\left.\mathrm{d}_{6}\right) \delta 7.56$ (d, J=8.77 $\mathrm{Hz}, 2 \mathrm{H}), 6.81$ (d, J=8.77 Hz, 2H), 6.37 (br s, 1H), 4.31 (s, 1H), 3.70 (s, 3H), 2.85 (s, 3H), 2.00 (br $\mathrm{s}, 2 \mathrm{H}), 1.47-1.58(\mathrm{~m}, 3 \mathrm{H}), 1.37-1.45(\mathrm{~m}, 2 \mathrm{H}), 1.20-1.37$ (m, 7H). (LCMS, ESI+) m/z Calcd. for $\left[\left(\mathrm{C}_{21} \mathrm{H}_{27} \mathrm{~N}_{3} \mathrm{O}_{3}\right)+\mathrm{H}\right]^{+}, 370$, found, 370 .

Chiral SFC separation of 2-amino-4-(3-hydroxyadamantan-1-yl)-4-(4-methoxyphenyl)-1-methyl1H-imidazol-5(4H)-one (IG, 21 x 250, 2-propanol with 0.25\% DMEA as modifier, 45\% modifier in $\mathrm{CO}_{2}$ ) afforded (5R)-2-amino-5-(3-hydroxyadamantan-1-yl)-5-(4-methoxyphenyl)-3-methyl3,5-dihydro-4H-imidazol-4-one (peak 2, Compound 6) and (5S)-2-amino-5-(3hydroxyadamantan-1-yl)-5-(4-methoxyphenyl)-3-methyl-3,5-dihydro-4H-imidazol-4-one (peak $1)$.

Compound 6: ${ }^{1} \mathrm{H}$ NMR (600 MHz, DMSO- $\left.d_{6}\right) \delta 7.59$ (d, $\left.J=8.9 \mathrm{~Hz}, 2 \mathrm{H}\right), 6.84(\mathrm{~d}, J=8.9 \mathrm{~Hz}$, $2 \mathrm{H}), 4.29(\mathrm{~s}, 1 \mathrm{H}), 3.73(\mathrm{~s}, 3 \mathrm{H}), 2.87(\mathrm{~s}, 3 \mathrm{H}), 1.91(\mathrm{~s}, 2 \mathrm{H}), 1.60-1.50(\mathrm{~m}, 3 \mathrm{H}), 1.46-1.40(\mathrm{~m}$, 2H), $1.39-1.21(\mathrm{~m}, 8 \mathrm{H}), 1.04(\mathrm{~d}, J=6.1 \mathrm{~Hz}, 1 \mathrm{H})$. (HRMS, ESI+) m/z Calcd. for $\left[\left(\mathrm{C}_{21} \mathrm{H}_{27} \mathrm{~N}_{3} \mathrm{O}_{3}\right)+\mathrm{H}\right]^{+}, 370.2130$, found, 370.2130. 
Compound 7: (R)-2-amino-5-(bicyclo[2.2.2]octan-1-yl)-5-(4-methoxyphenyl)-3-methyl-3,5dihydro-4H-imidazol-4-one

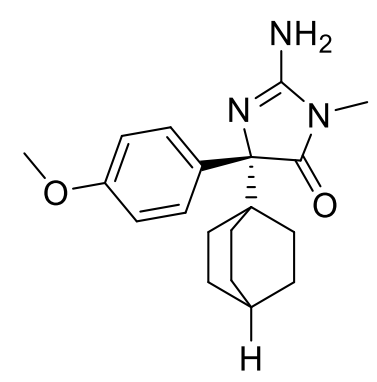

\section{Step 1:}

A mixture of 1-ethynylbicyclo[2.2.2]octane (70 mg, $0.52 \mathrm{mmol}$ ), 1-iodo-4-methoxybenzene (122 $\mathrm{mg}, 0.52 \mathrm{mmol}$ ), $\mathrm{Pd}\left(\mathrm{PPh}_{3}\right)_{2} \mathrm{Cl}_{2}$ (14.6 mg, $0.02 \mathrm{mmol}$ ), copper(I) iodide (5.0 mg, $0.026 \mathrm{mmol}$ ) and triethyl amine ( $3 \mathrm{ml}, 21.5 \mathrm{mmol})$ in acetonitrile $(3 \mathrm{ml})$ was degassed and backfilled with $\mathrm{N}_{2}$ (three times). The mixture was stirred at $45{ }^{\circ} \mathrm{C}$ for $3 \mathrm{~h}$, cooled to room temperature, and concentrated under vacuum. The resulting residue was purified by column chromatography on silica gel (Pet. ether/ethyl acetate $=10 / 1)$ to give 1-((4-methoxyphenyl)ethynyl)bicyclo[2.2.2] octane (50 mg, 0.20 mmol, $38 \%$ yield). ${ }^{1} \mathrm{H}$ NMR (400 MHz, $\left.\mathrm{CDCl}_{3}\right) \delta 7.30(\mathrm{~d}, J=8.77 \mathrm{~Hz}, 2 \mathrm{H}), 6.78(\mathrm{~d}, J=8.77 \mathrm{~Hz}$, 2H), 3.79 (s, 3H), 1.78 (br dd, $J=4.17,10.74 \mathrm{~Hz}, 6 \mathrm{H}), 1.58-1.62(\mathrm{~m}, 7 \mathrm{H})$.

\section{Step 2:}

To a solution of 1-((4-methoxyphenyl)ethynyl)bicyclo[2.2.2]octane $(50 \mathrm{mg}, 0.21 \mathrm{mmol})$ in acetone $(20 \mathrm{ml})$ was added a solution of $\mathrm{MgSO}_{4}(37.6 \mathrm{mg}, 0.31 \mathrm{mmol})$ and sodium bicarbonate $(10.5 \mathrm{mg}, 0.13 \mathrm{mmol})$ in water $(10 \mathrm{ml})$, followed by the addition of $\mathrm{KMnO}_{4}(99 \mathrm{mg}, 0.624 \mathrm{mmol})$ in one portion. The reaction was stirred for $12 \mathrm{~h}$ at $30{ }^{\circ} \mathrm{C}$. Water $(50 \mathrm{~mL})$ was added and the reaction mixture was extracted with ethyl acetate $(20 \mathrm{~mL} \times 3)$. The combined organic extracts were dried over $\mathrm{MgSO}_{4}$, filtered, and the filtrate was concentrated under vacuum. The residue was purified by column chromatography on silica gel (Pet. ether/ethyl acetate $=15 / 1$ to $5 / 1, \mathrm{v} / \mathrm{v}$ ) to give 1-(bicyclo[2.2.2]octan-1-yl)-2-(4-methoxyphenyl)ethane-1,2-dione (40 mg, $0.14 \mathrm{mmol}, 67 \%$ yield). ${ }^{1} \mathrm{H} \mathrm{NMR}\left(400 \mathrm{MHz}, \mathrm{CDCl}_{3}\right) \delta$ 7.74-7.78 (m, 2H), $6.95(\mathrm{~d}, J=9.21 \mathrm{~Hz}, 2 \mathrm{H}), 3.88(\mathrm{~s}, 3 \mathrm{H})$, $1.80-1.86(\mathrm{~m}, 6 \mathrm{H}), 1.66(\mathrm{dd}, J=3.07,5.70 \mathrm{~Hz}, 1 \mathrm{H}), 1.60(\mathrm{dt}, J=2.85,7.78 \mathrm{~Hz}, 6 \mathrm{H})$. 


\section{Step 3:}

A mixture of 1-(bicyclo[2.2.2]octan-1-yl)-2-(4-methoxyphenyl)ethane-1,2-dione (40 mg, 0.15 $\mathrm{mmol})$ and 1-methylguanidine hydrochloride $(80 \mathrm{mg}, 0.73 \mathrm{mmol})$ in 1,4-dioxane $(2 \mathrm{ml})$ and ethanol ( $2 \mathrm{~mL}$ ) was stirred at $30{ }^{\circ} \mathrm{C}$ for $5 \mathrm{~min}$. Then, a solution of $\mathrm{Na}_{2} \mathrm{CO}_{3}(78 \mathrm{mg}, 0.73 \mathrm{mmol})$ in water $(2 \mathrm{~mL})$ was added. The reaction was stirred at $85{ }^{\circ} \mathrm{C}$ for $5 \mathrm{~h}$. The mixture was cooled to room temperature and concentrated under vacuum. The resulting residue was purified by preHPLC (Xtimate C18 150*25mm*5um column, water(10mM NH${ }_{4} \mathrm{HCO}_{3}$ ):MeCN, 50\%B - 80\%B) to give 2-amino-4-(bicyclo[2.2.2]octan-1-yl)-4-(4-methoxyphenyl)-1-methyl-1H-imidazol5(4H)-one (31 mg, 0.09 mmol, $62 \%$ yield). ${ }^{1} \mathrm{H}$ NMR (400 MHz, DMSO-d 6 ) $\delta 7.55$ (br d, $J=8.33$ $\mathrm{Hz}, 2 \mathrm{H}), 6.79$ (br d, $J=8.33 \mathrm{~Hz}, 2 \mathrm{H}), 6.31$ (br s, 2H), 3.69 (s, 3H), 2.84 (s, 3H), 1.52 (br d, $J=$ $10.52 \mathrm{~Hz}, 3 \mathrm{H}), 1.18-1.44(\mathrm{~m}, 10 \mathrm{H})$. (LCMS, ESI+) m/z Calcd. for $\left[\left(\mathrm{C}_{19} \mathrm{H}_{25} \mathrm{~N}_{3} \mathrm{O}_{2}\right)+\mathrm{H}\right]^{+}, 328$, found 328.

Chiral SFC separation of 2-amino-4-(bicyclo[2.2.2]octan-1-yl)-4-(4-methoxyphenyl)-1-methyl$1 \mathrm{H}$-imidazol-5(4H)-one $\left(\mathrm{CCOF}_{4}, 21 \times 250\right.$, methanol $0.25 \%$ DMEA as modifier, $20 \%$ modifier in $\mathrm{CO}_{2}$ ) afforded (R)-2-amino-5-(bicyclo[2.2.2]octan-1-yl)-5-(4-methoxyphenyl)-3-methyl-3,5dihydro-4H-imidazol-4-one (peak 1, Compound 7) and (S)-2-amino-5-(bicyclo[2.2.2]octan-1-yl)5-(4-methoxyphenyl)-3-methyl-3,5-dihydro-4H-imidazol-4-one (peak 2).

Compound 7: ${ }^{1} \mathrm{H}$ NMR (499 MHz, DMSO- $\left.d_{6}\right) \delta 7.56(\mathrm{~d}, J=8.6 \mathrm{~Hz}, 2 \mathrm{H}), 6.81(\mathrm{~d}, J=8.6 \mathrm{~Hz}$, 2H), $3.71(\mathrm{~s}, 3 \mathrm{H}), 2.85$ (s, 3H), 1.89 (s, 3H), $1.61-1.50(\mathrm{~m}, 3 \mathrm{H}), 1.44-1.34(\mathrm{~m}, 6 \mathrm{H}), 1.30-1.22$ (m, 3H). (HRMS, ESI+) m/z Calcd. for $\left[\left(\mathrm{C}_{19} \mathrm{H}_{25} \mathrm{~N}_{3} \mathrm{O}_{2}\right)+\mathrm{H}\right]^{+}, 328.2025$, found, 328.2026. 
Compound 8: (R)-2-amino-5-(2-cyclohexylethyl)-3-methyl-5-phenyl-3,5-dihydro-4Himidazol-4-one<smiles>CN1C(=O)C(CCC2CCCCC2)(c2ccccc2)N=C1N</smiles>

5-(2-cyclohexylethyl)-2-imino-3-methyl-5-phenylimidazolidin-4-one was prepared in analogy to the procedures described in Method C in patent WO2005058311(A1) to provide 5-(3bromophenyl)-5-(2-cyclohexylethyl)-2-imino-3-methylimidazolidin-4-one (200 mg, $0.529 \mathrm{mmol}$ ) which was then reduced using $\mathrm{Pd} / \mathrm{C}(10 \%, 20 \mathrm{mg})$ catalyst in $\mathrm{MeOH}(38 \mathrm{~mL})$ under $\mathrm{H}_{2}$ atmosphere overnight. The resulting mixture was filtered through celite, concentrated in vacuo, and treated with $\mathrm{HCl} /$ ether to provide racemic 2-amino-5-(2-cyclohexylethyl)-3-methyl-5-phenyl-3,5dihydro-4H-imidazol-4-one as a $\mathrm{HCl}$ salt. The resulting racemic material was purified by chiral SFC (AD-H column, IPA/ $\mathrm{CO}_{2}$ with $0.25 \%$ DMEA modifier) to provide (R)-2-amino-5-(2cyclohexylethyl)-3-methyl-5-phenyl-3,5-dihydro-4H-imidazol-4-one (peak 1, Compound 8) and (S)-2-amino-5-(2-cyclohexylethyl)-3-methyl-5-phenyl-3,5-dihydro-4H-imidazol-4-one (peak 2).

Compound 8: ${ }^{1} \mathrm{H}$ NMR (600 MHz, DMSO-d6) $\delta$ 7.55-7.52 (m, 2H), 7.32-7.28 (m, 2H), 7.24$7.20(\mathrm{~m}, 1 \mathrm{H}), 6.61-6.28(\mathrm{~m}, 2 \mathrm{H}), 2.89(\mathrm{~s}, 3 \mathrm{H}), 1.89-1.76(\mathrm{~m}, 2 \mathrm{H}), 1.63-1.55(\mathrm{~m}, 4 \mathrm{H}), 1.19-1.04$ $(\mathrm{m}, 5 \mathrm{H}), 1.02-0.93(\mathrm{~m}, 2 \mathrm{H}), 0.81-0.73(\mathrm{~m}, 2 \mathrm{H})$. (HRMS, ESI+) m/z Calcd. for $\left[\left(\mathrm{C}_{18} \mathrm{H}_{25} \mathrm{~N}_{3} \mathrm{O}\right)+\mathrm{H}\right]^{+}$ 300.2076 , found, 300.2082 . 
Compound 9: (2R)-2-(adamantan-1-yl)-7-methyl-2-phenyl-5,6,7,8-tetrahydroimidazo[1,2a]pyrimidin-3(2H)-one<smiles>CC1CCN2C(=O)C(c3ccccc3)(C34CC5CC(CC(C5)C3)C4)N=C2N1</smiles>
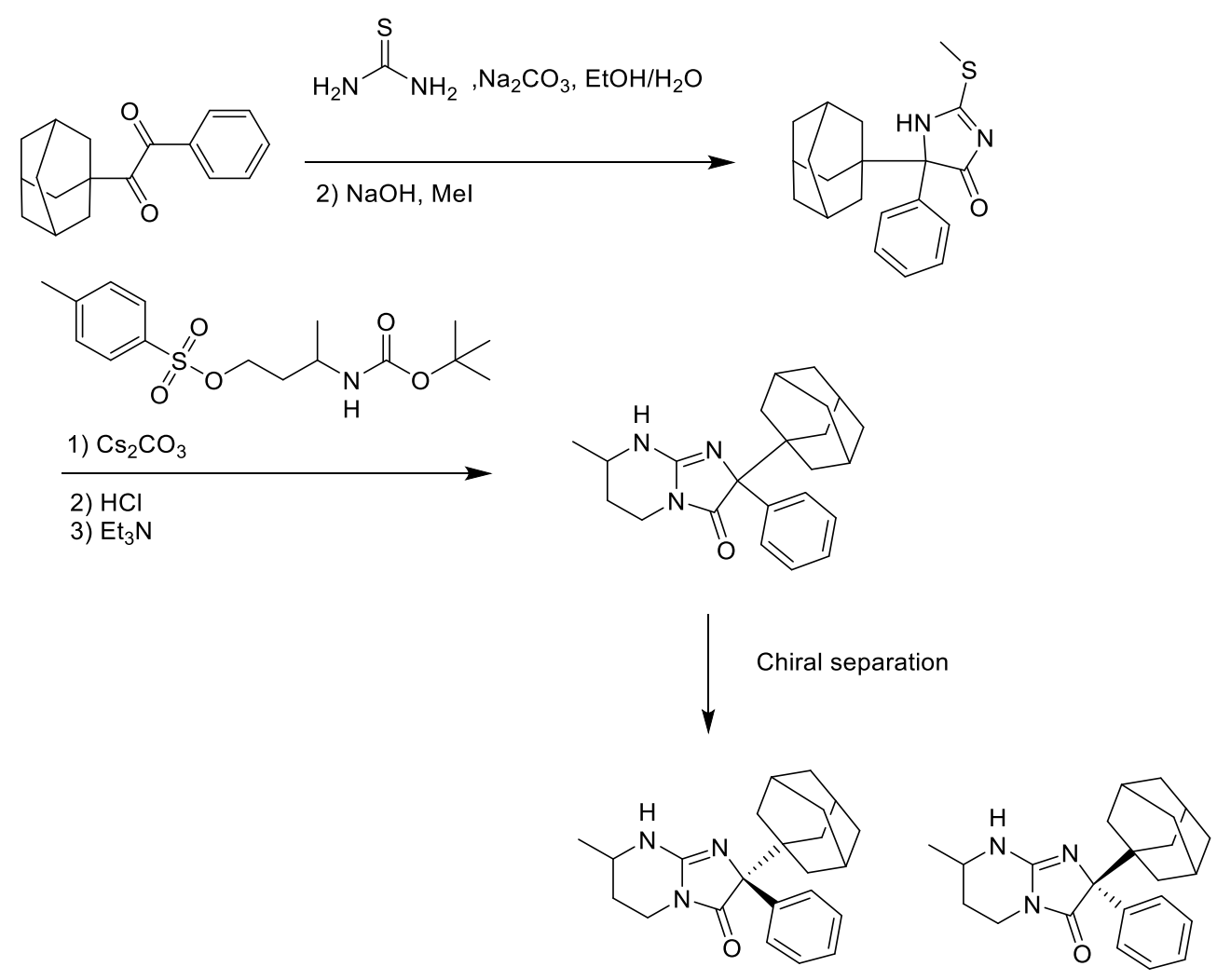

\section{Step 1:}

To a solution of 1-(adamantan-1-yl)-2-phenylethane-1,2-dione (690 mg, $2.31 \mathrm{mmol})$ in dioxane (6 $\mathrm{mL})$ and EtOH $(6 \mathrm{~mL})$ was added thiourea $(1.3 \mathrm{~g}, 11.56 \mathrm{mmol})$, the mixture was stirred at $28{ }^{\circ} \mathrm{C}$ for $15 \mathrm{~min}$. Then a solution of $\mathrm{Na}_{2} \mathrm{CO}_{3}(1.23 \mathrm{~g}, 11.56 \mathrm{mmol})$ in water $(6 \mathrm{~mL})$ was added and the mixture was stirred at $85^{\circ} \mathrm{C}$ for $12 \mathrm{~h}$. The resulting solution was cooled to room temperature and concentrated under vacuum. Water $(15 \mathrm{~mL})$ was added, and the mixture stirred at $28{ }^{\circ} \mathrm{C}$ for $30 \mathrm{~min}$ and filtered. The filter cake solid was dried in vacuo to afford 5-(adamantan-1-yl)-5-phenyl-2- 
thioxoimidazolidin-4-one (810 mg, quantitative yield) as a white solid, which was used directly in next step without further purification.

\section{Step 2:}

To a mixture of 5-(adamantan-1-yl)-5-phenyl-2-thioxoimidazolidin-4-one (800 mg, $2.45 \mathrm{mmol}$ ) and $\mathrm{NaOH}(98 \mathrm{mg}, 2.45 \mathrm{mmol})$ in THF $(5 \mathrm{ml}), \mathrm{MeOH}(5 \mathrm{~mL})$ and water $(5.0 \mathrm{ml})$ was added iodomethane $(1.17 \mathrm{~g}, 8.24 \mathrm{mmol})$. The resulting mixture was stirred at $25^{\circ} \mathrm{C}$ for $12 \mathrm{~h}$ and then concentrated under reduced pressure. Water $(15 \mathrm{~mL})$ was added and the resulting mixture was stirred at $25^{\circ} \mathrm{C}$ for $30 \mathrm{~min}$ and filtered. The filter cake solid was collected and dried in vacuo to afford 4-(adamantan-1-yl)-2-(methylthio)-4-phenyl-1H-imidazol-5(4H)-one (700 mg, 1.95 mmol, $80 \%$ yield) as a white solid, which was used directly in next step without further purification. ${ }^{1} \mathrm{H}$ NMR (400 MHz, DMSO-d $\left._{6}\right) 11.19$ (br s, 1H), 7.66 (br s, 2H), 7.14-7.43 (m, 3H), 2.53 (s, 3H), 1.88 (br s, 3H), 1.30-1.79 (m, 12H)

\section{Step 3:}

A solution of 4-(adamantan-1-yl)-2-(methylthio)-4-phenyl-1H-imidazol-5(4H)-one (200 mg, 0.59 mmol), 3-((tert-butoxycarbonyl)amino)butyl 4-methylbenzenesulfonate (303 $\mathrm{mg}, 0.88 \mathrm{mmol}$ ) and $\mathrm{Cs}_{2} \mathrm{CO}_{3}(574 \mathrm{mg}, 1.76 \mathrm{mmol})$ in DMF (4 ml) was stirred at $80^{\circ} \mathrm{C}$ for $12 \mathrm{~h}$. The mixture was then diluted with water $(60 \mathrm{~mL})$ and extracted with ethyl acetate $(30 \mathrm{~mL} \times 5)$. The combined organic layers were washed with brine $(30 \mathrm{~mL})$, dried over anhydrous sodium sulfate, filtered, and the filtrate was concentrated under reduced pressure. The resulting residue was purified by flash silica gel chromatography (ISCO $\AA_{0} ; 4$ g SepaFlash ${ }^{\circledR}$ Silica Flash Column, eluent of [0 8]\% ethyl acetate/petroleum ether gradient @ $45 \mathrm{~mL} / \mathrm{min}$ ) to give tert-butyl (4-(4-(adamantan-1-yl)-2(methylthio)-5-oxo-4-phenyl-4,5-dihydro-1H-imidazol-1-yl)butan-2-yl)carbamate (200 mg, 0.32 mmol, $55 \%$ yield) as a colorless oil. (LCMS, ESI+) m/z Calcd. for $\left[\left(\mathrm{C}_{29} \mathrm{H}_{41} \mathrm{~N}_{3} \mathrm{O}_{3} \mathrm{~S}\right)+\mathrm{H}\right]^{+} 512$, found, 512 .

\section{Step 4:}

A mixture of tert-butyl (4-(4-(adamantan-1-yl)-2-(methylthio)-5-oxo-4-phenyl-4,5-dihydro-1Himidazol-1-yl)butan-2-yl)carbamate $(200 \mathrm{mg}, 0.39 \mathrm{mmol})$ in $\mathrm{HCl} /$ dioxane $(4 \mathrm{M})(10 \mathrm{ml})$ was stirred at $20{ }^{\circ} \mathrm{C}$ for $2 \mathrm{~h}$. The mixture was concentrated to give crude 4-(adamantan-1-yl)-1-(3aminobutyl)-2-(methylthio)-4-phenyl-1H-imidazol-5(4H)-one (170 mg, $0.41 \mathrm{mmol})$ as a yellow 
oil, which was used in next step directly. (LCMS, ESI+) m/z Calcd. for $\left[\left(\mathrm{C}_{24} \mathrm{H}_{33} \mathrm{~N}_{3} \mathrm{OS}\right)+\mathrm{H}\right]^{+} 412$, found, 412 .

\section{Step 5:}

A mixture of 4-(adamantan-1-yl)-1-(3-aminobutyl)-2-(methylthio)-4-phenyl-1H-imidazol-5(4H)one (170 mg, $0.413 \mathrm{mmol})$ and triethyl amine $(0.576 \mathrm{ml}, 4.13 \mathrm{mmol})$ in $\mathrm{MeOH}(10 \mathrm{ml})$ was stirred at $85^{\circ} \mathrm{C}$ for $12 \mathrm{~h}$. The mixture was concentrated and purified by Prep-HPLC (Waters XSELECT C18 150*30mm*5um column, water(0.1\% TFA):MeCN 30\%B-60\%B) to give 2-(adamantan-1yl)-7-methyl-2-phenyl-5,6,7,8-tetrahydroimidazo[1,2-a]pyrimidin-3(2H)-one (50 mg, $0.14 \mathrm{mmol}$, $33 \%$ yield) as a white solid. (LCMS, ESI+) m/z Calcd. for $\left[\left(\mathrm{C}_{23} \mathrm{H}_{29} \mathrm{~N}_{3} \mathrm{O}\right)+\mathrm{H}\right]^{+} 364$, found, 364 .

2-(adamantan-1-yl)-7-methyl-2-phenyl-5,6,7,8-tetrahydroimidazo[1,2-a]pyrimidin-3(2H)-one (50 mg, $0.138 \mathrm{mmol}$ ) was further purified by SFC (DAICEL CHIRALPAK IC(250mm*30mm,10um) column, IPA, $0.1 \% \mathrm{NH}_{3} \mathrm{H}_{2} \mathrm{O}$ as modifier, $45 \%$ modified in $\mathrm{CO}_{2}$ ) to give (2R)-2-(adamantan-1-yl)-7-methyl-2-phenyl-5,6,7,8-tetrahydroimidazo[1,2-a]pyrimidin-3(2H)one (peak 1, Compound 9) and (2S)-2-(adamantan-1-yl)-7-methyl-2-phenyl-5,6,7,8tetrahydroimidazo[1,2-a]pyrimidin-3(2H)-one (peak 2).

Compound 9: ${ }^{1} \mathrm{H}$ NMR (400 MHz, METHANOL-d $\left.{ }_{4}\right) \delta 7.69$ (br d, $\left.J=7.02 \mathrm{~Hz}, 2 \mathrm{H}\right), 7.18-7.31$ $(\mathrm{m}, 3 \mathrm{H}), 3.65(\mathrm{td}, J=4.66,12.61 \mathrm{~Hz}, 1 \mathrm{H}), 3.47-3.56(\mathrm{~m}, 1 \mathrm{H}), 1.95-2.05(\mathrm{~m}, 1 \mathrm{H}), 1.91$ (br s, $3 \mathrm{H})$, $1.82(\mathrm{br} \mathrm{d}, J=11.84 \mathrm{~Hz}, 3 \mathrm{H}), 1.61-1.69(\mathrm{~m}, 3 \mathrm{H}), 1.46-1.57(\mathrm{~m}, 7 \mathrm{H}), 1.24-1.37$ (m, 1H), $1.22(\mathrm{~d}, J$ $=6.14 \mathrm{~Hz}, 3 \mathrm{H}) .(\mathrm{HRMS}, \mathrm{ESI}+) \mathrm{m} / \mathrm{z}$ Calcd. for $\left[\left(\mathrm{C}_{23} \mathrm{H}_{29} \mathrm{~N}_{3} \mathrm{O}\right)+\mathrm{H}\right]^{+}:$364.2389, found 364.2397.

Compound 10: (2R)-2-(adamantan-1-yl)-7-ethyl-2-phenyl-5,6,7,8-tetrahydroimidazo[1,2a]pyrimidin-3(2H)-one

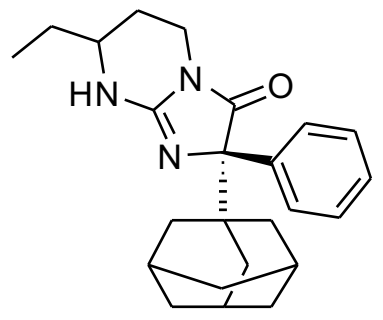

Step 1: 
A solution of 4-(adamantan-1-yl)-2-(methylthio)-4-phenyl-1H-imidazol-5(4H)-one (200 mg, 0.59 mmol), 3-((tert-butoxycarbonyl)amino)pentyl 4-methylbenzenesulfonate (252 mg, $0.71 \mathrm{mmol})$ and $\mathrm{Cs}_{2} \mathrm{CO}_{3}(574 \mathrm{mg}, 1.76 \mathrm{mmol})$ in DMF $(3 \mathrm{ml})$ was stirred at $80^{\circ} \mathrm{C}$ for $12 \mathrm{~h}$. The mixture was diluted with water $(60 \mathrm{~mL})$ and extracted with EtOAc $(30 \mathrm{~mL}$ x 5). The combined organic layers were washed with brine $(30 \mathrm{~mL})$, dried over anhydrous sodium sulfate, filtered, and the filtrate was concentrated under vacuum to give tert-butyl (1-(4-(adamantan-1-yl)-2-(methylthio)-5-oxo4-phenyl-4,5-dihydro-1H-imidazol-1-yl)pentan-3-yl)carbamate (300 mg, $0.57 \mathrm{mmol}$ ), which was used in next step directly. (LCMS, ESI+) m/z Calcd. for $\left[\left(\mathrm{C}_{30} \mathrm{H}_{43} \mathrm{~N}_{3} \mathrm{O}_{3} \mathrm{~S}\right)+\mathrm{H}\right]^{+}: 526$, found 526 .

\section{Step 2:}

A solution of tert-butyl (1-(4-(adamantan-1-yl)-2-(methylthio)-5-oxo-4-phenyl-4,5-dihydro-1Himidazol-1-yl)pentan-3-yl)carbamate (300 mg, $0.57 \mathrm{mmol}$ ) in $\mathrm{HCl} / \mathrm{EtOAc}(4 \mathrm{M})$ (5 ml) was stirred at $15{ }^{\circ} \mathrm{C}$ for 1.5 hours. The mixture was concentrated to give 4-(adamantan-1-yl)-1-(3aminopentyl)-2-(methylthio)-4-phenyl-1H-imidazol-5(4H)-one (250 mg, $0.587 \mathrm{mmol}$ ), which was used in next step directly. (LCMS, ESI+) m/z Calcd. for $\left[\left(\mathrm{C}_{25} \mathrm{H}_{35} \mathrm{~N}_{3} \mathrm{OS}\right)+\mathrm{H}\right]^{++}: 426$, found 426.

\section{Step 3:}

A mixture of 4-(adamantan-1-yl)-1-(3-aminopentyl)-2-(methylthio)-4-phenyl-1H-imidazol5(4H)-one (300 mg, $0.71 \mathrm{mmol})$ and TEA $(0.98 \mathrm{ml}, 7.1 \mathrm{mmol})$ in $\mathrm{MeOH}(10 \mathrm{ml})$ was stirred at 85 ${ }^{\circ} \mathrm{C}$ for $12 \mathrm{~h}$. The mixture was cooled to room temperature and concentrated under vacuum. The resulting residue was purified by Prep-HPLC (Waters XSELECT C18 150*30mm*5um column, water(0.1\% TFA):MeCN 30\%B-60\%B) to give 2-(adamantan-1-yl)-7-ethyl-2-phenyl-5,6,7,8tetrahydroimidazo[1,2-a]pyrimidin-3(2H)-one (100 mg, $0.26 \mathrm{mmol}, 37 \%$ yield) as a white solid. (LCMS, ESI+) m/z Calcd. for $\left[\left(\mathrm{C}_{24} \mathrm{H}_{31} \mathrm{~N}_{3} \mathrm{O}\right)+\mathrm{H}\right]^{+}:$378, found 378 .

Chiral SFC separation of 2-(adamantan-1-yl)-7-ethyl-2-phenyl-5,6,7,8-tetrahydroimidazo[1,2a]pyrimidin-3(2H)-one (DAICEL CHIRALCEL OD-H (250mm*30mm, 5 um) column, EtOH, $0.1 \% \mathrm{NH}_{3} \mathrm{H}_{2} \mathrm{O}$ as modifier, $40 \%$ modifier in $\mathrm{CO}_{2}$ ) afforded (2R)-2-(adamantan-1-yl)-7-ethyl-2phenyl-5,6,7,8-tetrahydroimidazo[1,2-a]pyrimidin-3(2H)-one (peak 1, Compound 10) and (2S)2-(adamantan-1-yl)-7-ethyl-2-phenyl-5,6,7,8-tetrahydroimidazo[1,2-a]pyrimidin-3(2H)-one (peak 2). 
Compound 10: ${ }^{1} \mathrm{H}$ NMR (400 MHz, DMSO-d6) $\delta$ 7.65-7.67 (m, 2H), 7.21-7.38 (m, 3H), 3.51$3.54(\mathrm{~m}, 1 \mathrm{H}), 3.2(\mathrm{br}, 2 \mathrm{H}), 1.87(\mathrm{br}, 4 \mathrm{H}), 1.68-1.71(\mathrm{~m}, 4 \mathrm{H}), 1.43-1.56(\mathrm{~m}, 4 \mathrm{H}), 1.33-1.43(\mathrm{~m}, 8 \mathrm{H})$, $0.85(\mathrm{t}, J=7.2 \mathrm{~Hz}, 3 \mathrm{H})$. (HRMS, ESI +$) \mathrm{m} / \mathrm{z}$ Calcd. for $\left[\left(\mathrm{C}_{24} \mathrm{H}_{31} \mathrm{~N}_{3} \mathrm{O}\right)+\mathrm{H}\right]^{+}: 378.2545$, found 378.2550 .

\section{Cloning, Expression, and Purification of Protein for Crystallography}

Human PRMT5 (amino acids 2-637) with an N-terminal Flag tag and MEP50 (amino acids 2-342) with an $\mathrm{N}$-terminal $8 \mathrm{x}$-histidine tag was cloned into a $\mathrm{pFastBac}$ vector and used to transform High Five $^{\mathrm{TM}}$ (BTI-TN-5B1-4) competent cells (ThermoFisher). Cells were grown in Express Five SFM media (Gibco) to a density of $1.5 \times 10^{6}$ at $27^{\circ} \mathrm{C}$ for $48 \mathrm{hrs}$ with an infected ratio ofPRMT5/MEP50: 1:200/1:50 (v/v). Harvested cells were sonicated by first resuspending the pellet in buffer A (50 $\mathrm{mM}$ Tris-HCl, $500 \mathrm{mM} \mathrm{NaCl}, 100 \mathrm{mM}$ Glu, $100 \mathrm{mM}$ Arg, $1 \mathrm{mM}$ TCEP, $\mathrm{pH}$ 8.0) with a ratio of 6 $\mathrm{mL}$ per gram of pellet, followed by sonication at $200 \mathrm{~W}$ for $3 \mathrm{~s}$ on and $3 \mathrm{~s}$ off for 20 minutes. Lysate was centrifuged at $13,500 \mathrm{rpm}$ for $30 \mathrm{~min}$ at $4^{\circ} \mathrm{C}$ and supernatant was collected. Clarified lysate in buffer B (50 mM Tris-HCl, $500 \mathrm{mM} \mathrm{NaCl}, 100$ mM Glu, 100 mM Arg, 1 mM TCEP, pH 8.0) was IMAC-purified using pre-equilibrated Ni-NTA resin (Qiagen) and washed with buffers C and D until no protein was detected in flow through (Buffer C: $50 \mathrm{mM}$ Tris- $\mathrm{HCl}, 250 \mathrm{mM} \mathrm{NaCl}, 1 \mathrm{mM}$ TCEP, pH 8.0, $20 \mathrm{mM}$ imidazole; Buffer D: Buffer C with $50 \mathrm{mM}$ imidazole).PRMT5:MEP50 protein was eluted with buffer $\mathrm{E}$ (Buffer $\mathrm{C}$ with $250 \mathrm{mM}$ imidazole). Eluate was pooled and dialyzed against Buffer $\mathrm{F}$ (20 mM Tris, $150 \mathrm{mM} \mathrm{NaCl}, 5 \%$ (v/v) glycerol, $\mathrm{pH} 8.0$ ) at $4^{\circ} \mathrm{C}$ overnight. Protein was further purified via Flag column chromatography using a pre-equilibrated (Buffer F) ANTI-FLAG M2 affinity gel column (Sigma-Aldrich). Column was eluted with buffer G (200 $\mu \mathrm{g} / \mathrm{ml}$ peptide, $20 \mathrm{mM}$ Tris, $150 \mathrm{mM} \mathrm{NaCl}, 5 \%$ glycerol, $\mathrm{pH}$ 7.8) until no protein was detected in flow-through, followed by a column wash in buffer $\mathrm{H}(0.1 \mathrm{M}$ glycine-HCl, $\mathrm{pH}$ 3.5). The FLAG column eluate was concentrated and centrifuged at $13,500 \mathrm{rpm}$ for $10 \mathrm{~min}$ at $4^{\circ} \mathrm{C}$. The supernatant was then loaded onto a Superdex 200 column (GE Healthcare), which was preequilibrated with buffer I (10 mM Hepes, 150mM NaCl, $1 \mathrm{mM}$ TCEP, 10\%(v/v) glycerol, $\mathrm{pH} 8.0)$ and run at a flow rate of $1.0 \mathrm{~mL} / \mathrm{min}$. Final purified protein was concentrated to approximately $15 \mathrm{mg} / \mathrm{mL}$, centrifuged at 13,500 rpm for $10 \mathrm{~min}$ at $4^{\circ} \mathrm{C}$, and the supernatant was aliquoted, flash frozen, and stored at $-80^{\circ} \mathrm{C}$ until utilized in crystallography studies. 


\section{Crystallization and Structural Analysis}

X-ray diffraction-quality crystals of the PRMT5:MEP50 protein complex were obtained by hanging drop vapor diffusion at $18^{\circ} \mathrm{C}$ by mixing a $1: 1$ ratio of the protein solution $(15 \mathrm{mg} / \mathrm{mL}$ preincubated with $2 \mathrm{mM}$ SAM and $2 \mathrm{mM}$ compound at $4^{\circ} \mathrm{C}$ for $3 \mathrm{hr}$, centrifuged for $30 \mathrm{~min}$ at $13,000 \mathrm{rpm}$ ) and a precipitant solution containing $0.1 \mathrm{M}$ sodium citrate $\mathrm{pH}$ 6.0, 0.2 $\mathrm{M}$ sodium acetate, $10-12 \%$ PEG 4000, and streak seeding all drops. Crystals were seen after approximately 24 hours.

These crystals diffracted to nominal resolutions of 2.6-2.7 $\AA$ and belonged to the space group $I 222$ with one PRMT5:MEP50 dimer in the asymmetric unit and the following approximate unit cell dimensions: $a=102 \AA, b=139 \AA$, and $c=178 \AA$. Crystals were transferred to cryoprotectant containing 0.1 M sodium citrate pH 6.0, 0.2 M sodium acetate, 10-12\% PEG 4000, and 20\% ethylene glycol prior to being harvested and plunged into LN2 prior to synchrotron data collection. X-ray data sets were collected at Shanghai Synchrotron Radiation Facility Beamline BL19U1 (Compound 1a) and Canadian Macromolecular Crystallography Facility Beamline CMCF-ID (08ID-1) at the Canadian Light Source (Compound 8), using Pilatus 6M detectors (Dectris). Data were processed using HKL3000 ${ }^{1}$, refined using Refmac5 $5^{2,3}$ and autoBUSTER ${ }^{4}$, with manual compound building using $\operatorname{Coot}^{5}$, compound geometrical restraints prepared using grade ${ }^{6}$, and figures prepared using PyMOL ${ }^{7}$. Relevant X-ray data collection and refinement statistics are listed in Table S1.

Part of the research described in this paper was performed at the Canadian Light Source, a national research facility of the University of Saskatchewan, which is supported by the Canada Foundation for Innovation (CFI), the Natural Sciences and Engineering Research Council (NSERC), the National Research Council (NRC), the Canadian Institutes of Health Research (CIHR), the Government of Saskatchewan, and the University of Saskatchewan. 
Table S1. Crystal Data Collection and Refinement Statistics Table

\begin{tabular}{|c|c|c|}
\hline PDB code & 6UXX & 6UXY \\
\hline Compound name & Compound 1a & Compound 8 \\
\hline \multicolumn{3}{|l|}{ Data collection } \\
\hline Space group & I222 & I222 \\
\hline Cell dimensions a, b, c $(\AA)$ & $103.1,138.8,178.6$ & $101.8,139.2,179.4$ \\
\hline Resolution $(\AA)$ & $50.00-2.69(2.79-2.69)^{*}$ & $60.61-2.35(2.41-2.35)$ \\
\hline Rmerge & $0.07(0.65)$ & $0.09(1.51)$ \\
\hline $\mathrm{I} / \sigma \mathrm{I}$ & $23.9(2.2)$ & $15.5(1.9)$ \\
\hline Completeness (\%) & $99.0(94.4)$ & $99.9(99.8)$ \\
\hline Redundancy & $6.4(5.6)$ & $13.5(13.4)$ \\
\hline Refinement & & \\
\hline Resolution $(\AA)$ & $36.5-2.7$ & $46.5-2.6$ \\
\hline No. reflections & 35526 & 41318 \\
\hline Rwork / Rfree & $0.22 / 0.27$ & $0.21 / 0.26$ \\
\hline \multicolumn{3}{|l|}{ No. atoms } \\
\hline Protein & 7272 & 7312 \\
\hline Ligand & 26 & 22 \\
\hline Solvent & 57 & 241 \\
\hline \multicolumn{3}{|l|}{ B-factors } \\
\hline Protein $(\AA 22)$ & 91.6 & 83.0 \\
\hline Ligands (̊̊2) & 64.4 & 56.0 \\
\hline Solvent (Å2) & 71.1 & 71.5 \\
\hline \multicolumn{3}{|l|}{ R.m.s. deviations } \\
\hline Bond lengths $(\AA)$ & 0.010 & 0.010 \\
\hline Bond angles $\left({ }^{\circ}\right)$ & 1.18 & 0.88 \\
\hline
\end{tabular}




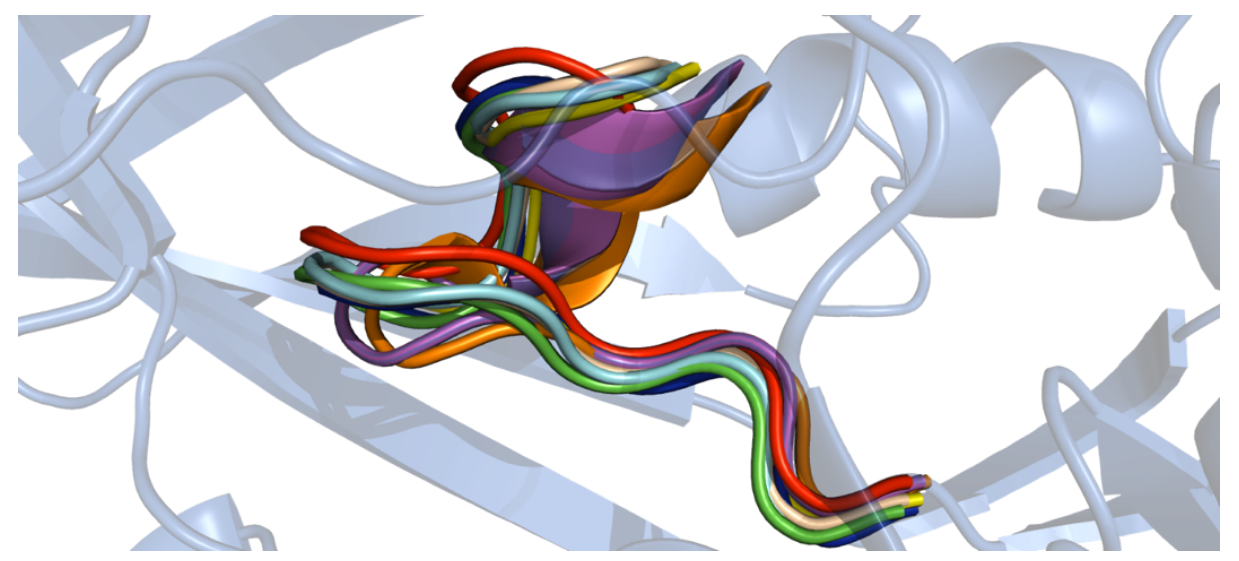

Figure S4. A cartoon overlay of PRMT1 (3q7e, red), PRMT2 (5jmq, green), PRMT3 (4hsg, blue), PRMT4 (5ih3, yellow), PRMT5 (6ckc, magenta), PRMT6 (5egs, cyan), PRMT7 (5eku, orange), PRMT8 (5dst, wheat) highlight the conserved structure of the 12-residue loop in the orthosteric conformation.

$\begin{array}{lll}\text { PRMT5 } & \text { SELLGSFADNEL } & 12 \\ \text { PRMT7 } & \text { SEIFGTMMLGES } & 12 \\ \text { PRMT4 } & \text { SEPMGYMLFNER } & 12 \\ \text { PRMT2 } & \text { SEWMGTCLLFEF } & 12 \\ \text { PRMT1 } & \text { SEWMGYCLFYES } & 12 \\ \text { PRMT8 } & \text { SEWMGYCLFYES } & 12 \\ \text { PRMT3 } & \text { SEWMGYFLLFES } & 12 \\ \text { PRMT6 } & \text { SEWMGYGLLHES } & 12 \\ & * *: * & \text { * }\end{array}$

Figure S5. Alignment of the loop residues for each PRMT with a known public structure, listed in order of highest sequence identity to PRMT5.

Table S2. C $\alpha$ RMSD values for the 12 residue loop

\begin{tabular}{|c|c|c|c|c|c|c|c|c|}
\hline & PRMT1 & PRMT2 & PRMT3 & PRMT4 & PRMT5 & PRMT6 & PRMT7 & PRMT8 \\
\hline PRMT1 & 0.00 & 1.33 & 1.27 & 1.49 & 1.98 & 1.25 & 2.67 & 1.22 \\
\hline PRMT2 & 1.33 & 0.00 & 1.22 & 0.95 & 1.60 & 0.87 & 2.31 & 0.53 \\
\hline PRMT3 & 1.27 & 1.22 & 0.00 & 1.20 & 1.57 & 1.56 & 2.11 & 1.34 \\
\hline PRMT4 & 1.49 & 0.95 & 1.20 & 0.00 & 1.03 & 1.12 & 1.70 & 0.77 \\
\hline PRMT5 & 1.98 & 1.60 & 1.57 & 1.03 & 0.00 & 1.70 & 1.04 & 1.42 \\
\hline PRMT6 & 1.25 & 0.87 & 1.56 & 1.12 & 1.70 & 0.00 & 2.37 & 0.57 \\
\hline PRMT7 & 2.67 & 2.31 & 2.11 & 1.70 & 1.04 & 2.37 & 0.00 & 2.14 \\
\hline PRMT8 & 1.22 & 0.53 & 1.34 & 0.77 & 1.42 & 0.57 & 2.14 & 0.00 \\
\hline
\end{tabular}




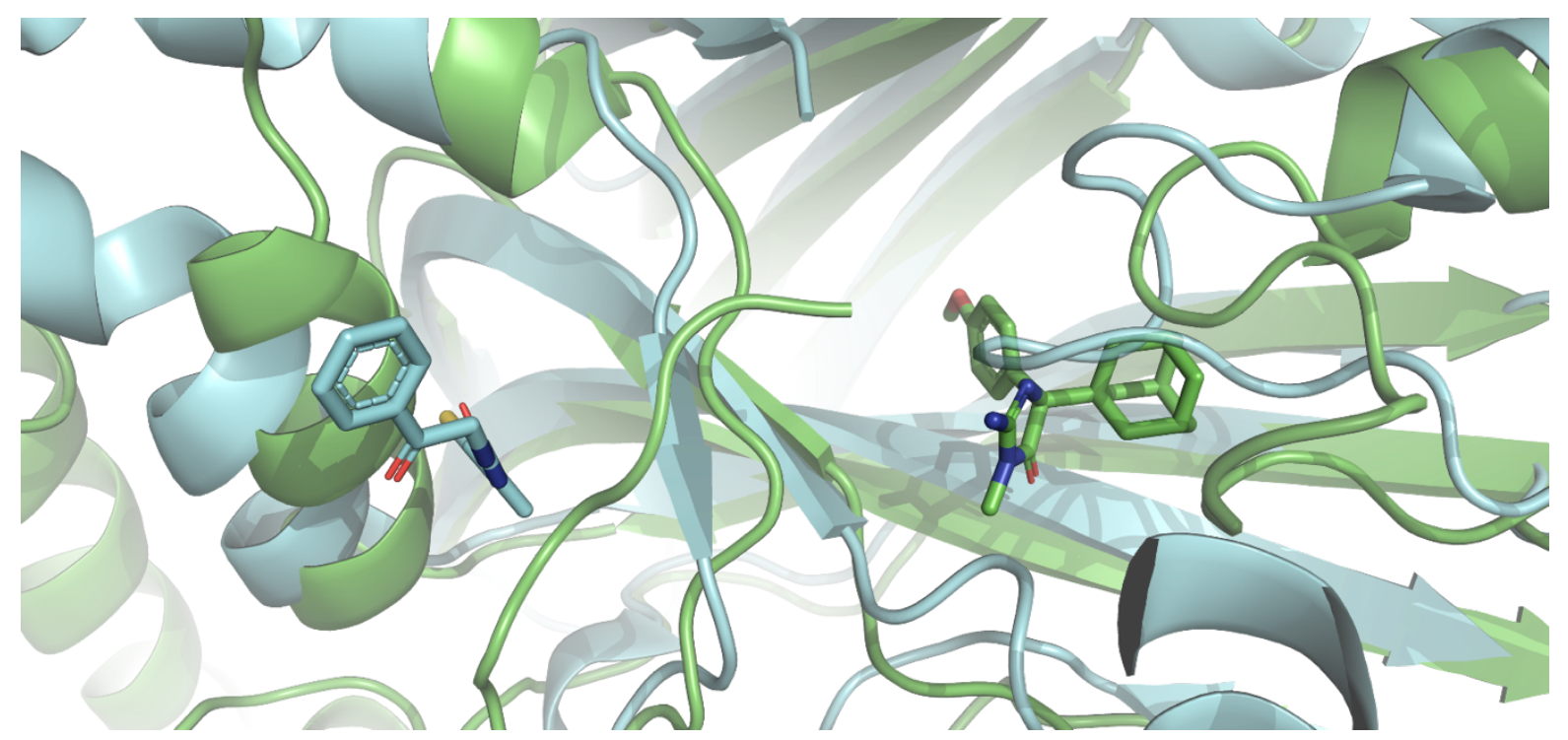

Figure S6. Overlay of PRMT3 and PRMT5 crystal structures. The PRMT3 allosteric inhibitor (PDB 4shg) is shown in cyan, the allosteric PRMT5 inhibitor is shown in green (PDB 6uxx). The allosteric inhibitors for these two PRMT subtypes bind to different pockets.

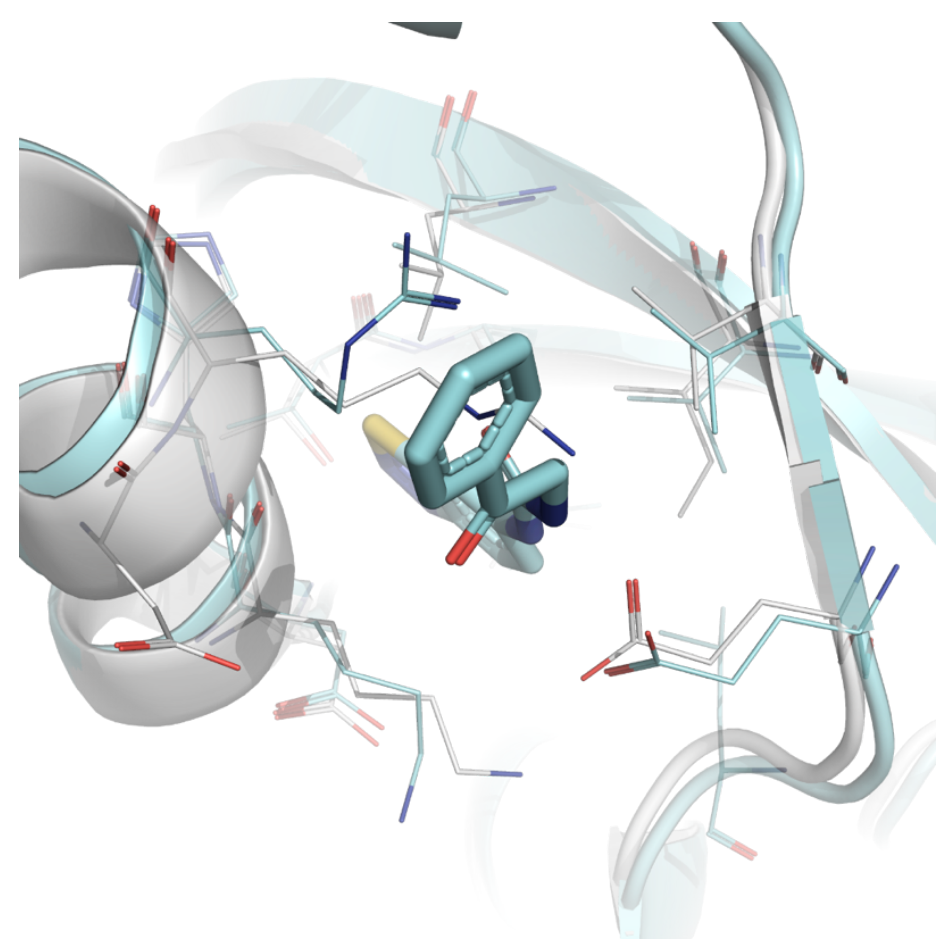

Figure S7. Binding site of the allosteric PRMT3 compound. Overlay of two PRMT3 crystal structures, bound with an allosteric inhibitor (cyan, PDB 4shg) and without (gray, PDB 1f31). Binding of the allosteric inhibitor results in adjustment of the sidechains in this pocket but does not result in major backbone movement. 
Synthetic Procedures and Characterization Data for Mosher Amides of Compound 1a

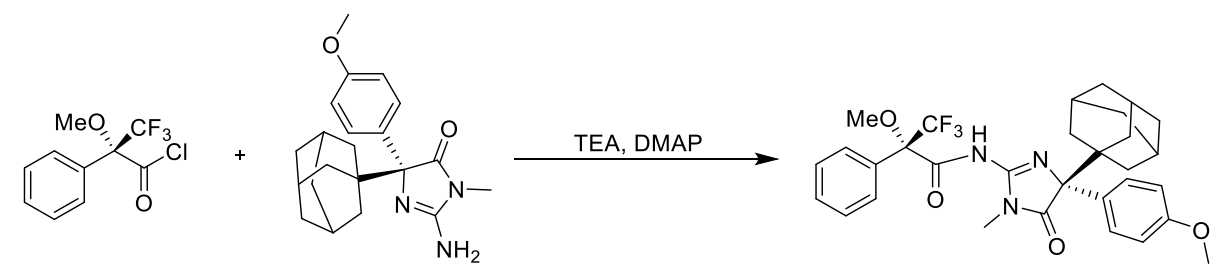

(2S)-N-((4R)-4-(adamantan-1-yl)-4-(4-methoxyphenyl)-1-methyl-5-oxo-4,5-dihydro-1Himidazol-2-yl)-3,3,3-trifluoro-2-methoxy-2-phenylpropanamide: TEA (13 $\mu 1,0.09 \mathrm{mmol}$ ), DMAP (1.2 mg, $10 \mu \mathrm{mol}$ ), and (R)-3,3,3-trifluoro-2-methoxy-2-phenylpropanoyl chloride $8.6 \mu \mathrm{l}$, $0.05 \mathrm{mmol})$ were added to a solution of Compound 1a $(10.8 \mathrm{mg}, 0.03 \mathrm{mmol})$ in $\mathrm{CDCl}_{3}(611 \mu \mathrm{l})$. The reaction mixture was stirred at room temperature for 6 hours and then left in the refrigerator overnight. The resulting solution was used for NMR characterization directly. (LCMS, ESI+) m/z Calcd. for $\left[\left(\mathrm{C}_{31} \mathrm{H}_{34} \mathrm{~F}_{3} \mathrm{~N}_{3} \mathrm{O}_{4}\right)+\mathrm{H}\right]^{+}, 570$, found, 570 .

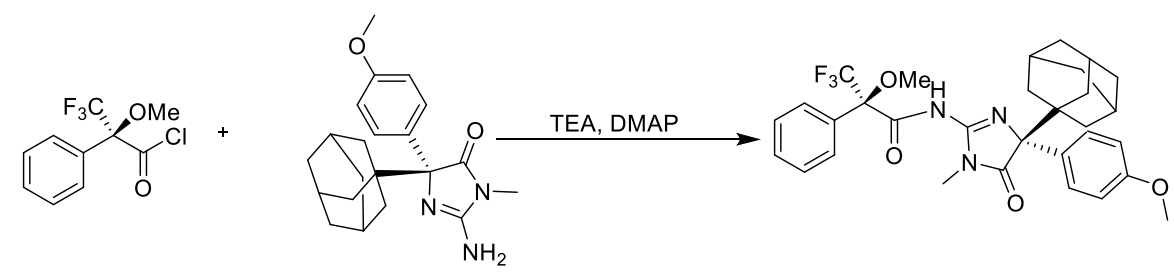

(2R)-N-((4R)-4-(adamantan-1-yl)-4-(4-methoxyphenyl)-1-methyl-5-oxo-4,5-dihydro-1Himidazol-2-yl)-3,3,3-trifluoro-2-methoxy-2-phenylpropanamide: TEA (12 $\mu 1,0.08 \mathrm{mmol})$, DMAP (1.6 mg, $0.01 \mathrm{mmol}$ ) and (S)-3,3,3-trifluoro-2-methoxy-2-phenylpropanoyl chloride 7.8 $\mu 1,0.04 \mathrm{mmol})$ were added to a solution of Compound 1a $(9.8 \mathrm{mg}, 0.03 \mathrm{mmol})$ in $\mathrm{CDCl}_{3}(277$ $\mu 1)$. The reaction mixture was stirred at room temperature for 2 hours and then used for NMR characterization directly. (LCMS, ESI+) m/z Calcd. for $\left[\left(\mathrm{C}_{31} \mathrm{H}_{34} \mathrm{~F}_{3} \mathrm{~N}_{3} \mathrm{O}_{4}\right)+\mathrm{H}\right]^{+}, 570$, found, 570 .

${ }^{1} \mathrm{H},{ }^{13} \mathrm{C}$, PS-HSQC, HMBC, and COSY were performed at $25^{\circ} \mathrm{C}$ at $500 \mathrm{MHz}$ on the crude reaction mixtures in $\mathrm{CDCl}_{3}$ and were utilized to fully assign both ${ }^{1} \mathrm{H}$ and ${ }^{13} \mathrm{C}$ shifts of (2S)-N-((4R)-4(adamantan-1-yl)-4-(4-methoxyphenyl)-1-methyl-5-oxo-4,5-dihydro-1H-imidazol-2-yl)-3,3,3trifluoro-2-methoxy-2-phenylpropanamide and (2R)-N-((4R)-4-(adamantan-1-yl)-4-(4methoxyphenyl)-1-methyl-5-oxo-4,5-dihydro-1H-imidazol-2-yl)-3,3,3-trifluoro-2-methoxy-2phenylpropanamide. PS-HSQC singlets were used to assign the absolute position of ${ }^{1} \mathrm{H}$ shifts. ${ }^{15}$ All NMR spectra were referenced to TMS at $0.0 \mathrm{ppm}$. 
(2R)-N-((4R)-4-(adamantan-1-yl)-4-(4-methoxyphenyl)-1-methyl-5-oxo-4,5-dihydro-1Himidazol-2-yl)-3,3,3-trifluoro-2-methoxy-2-phenylpropanamide. ${ }^{13} \mathrm{C}$ NMR $(126 \mathrm{MHz}$, Chloroform- $d$ ) $\delta 179.5,172.4,160.3,158.5,133.2,127.9,127.5,127.1,126.6,126.6,123.6$ (dd, $J=288.6,79.7 \mathrm{~Hz}), 123.2,112.2,84.9$ (q, $J=84.9 \mathrm{~Hz}), 72.0,54.3,39.5,35.2,34.8,27.1,24.4$. ${ }^{1} \mathrm{H}$ NMR (500 MHz, Chloroform- $d$ ) $\delta 9.97$ (s, 1H), 7.55-7.52 (m, overlapped, 2H), 7.41 (d, $J=$ $8.9 \mathrm{~Hz}, 2 \mathrm{H}), 7.31-7.27$ (m, overlapped, 3H), 6.84 (d, J=8.9 Hz, 2H), 3.75 (s, 3H), 3.56 (br s, 3H), 2.93 (s, 3H), 1.93 (p, J=3.0 Hz, 3H), $1.77-1.69(\mathrm{~m}, 3 \mathrm{H}), 1.57$ (d, $J=11.9 \mathrm{~Hz}, 3 \mathrm{H}), 1.47$ $(\mathrm{d}, J=11.9 \mathrm{~Hz}, 3 \mathrm{H}), 1.39-1.31(\mathrm{~m}, 3 \mathrm{H})$.

(2S)-N-((4R)-4-(adamantan-1-yl)-4-(4-methoxyphenyl)-1-methyl-5-oxo-4,5-dihydro-1Himidazol-2-yl)-3,3,3-trifluoro-2-methoxy-2-phenylpropanamide. ${ }^{13} \mathrm{C}$ NMR $(126 \mathrm{MHz}$, Chloroform- $d$ ) $\delta 179.5,172.4,160.2,158.5,133.3,127.9,127.5,127.1,126.7,123.6(\mathrm{dd}, J=$ 288.6, 80.8 Hz), 123.2, 112.2, 84.9 (d, $J=26.0$ ), 71.9, 54.3, 54.3, 39.6, 35.2, 34.8, 27.1, 24.4. ${ }^{1} \mathrm{H}$ NMR (500 MHz, Chloroform-d) $\delta 9.97$ (s, 1H), 7.54-7.51 (m, overlapped, 2H), 7.42 (d, J=9.0 Hz, 2H), 7.32 - 7.28 (m, overlapped, 3H), 6.83 (d, J=8.9 Hz, 2H), 3.74 (s, 3H), 3.53 (br s, 3H), $2.92(\mathrm{~s}, 3 \mathrm{H}), 1.93(\mathrm{p}, J=3.3 \mathrm{~Hz}, 3 \mathrm{H}), 1.70(\mathrm{dd}, J=12.0,2.6 \mathrm{~Hz}, 3 \mathrm{H}), 1.58(\mathrm{~d}, J=12.5 \mathrm{~Hz}, 3 \mathrm{H})$, $1.47(\mathrm{~d}, J=12.4 \mathrm{~Hz}, 3 \mathrm{H}), 1.34(\mathrm{dd}, J=11.8,2.2 \mathrm{~Hz}, 3 \mathrm{H})$.

Table S3. Corrected Mean Average Error for DFT chemical shifts calculated at the IEFPCMmPW1PW91/6-311+G(2d,p)// M062X/6-311+G(2d,p) level for ${ }^{13} \mathrm{C}$ and and WP04/aug-ccpVDZ//B3LYP/6-31+G(d,p) level for ${ }^{1} \mathrm{H}$ for both (2S)-N-((4R)-4-(adamantan-1-yl)-4-(4methoxyphenyl)-1-methyl-5-oxo-4,5-dihydro-1H-imidazol-2-yl)-3,3,3-trifluoro-2-methoxy-2phenylpropanamide and (2R)-N-((4R)-4-(adamantan-1-yl)-4-(4-methoxyphenyl)-1-methyl-5oxo-4,5-dihydro-1H-imidazol-2-yl)-3,3,3-trifluoro-2-methoxy-2-phenylpropanamide indicating position 4 of the Mosher's amides have an $R$ absolute configuration, corresponding to a 5- $R$ configuration in Compound 1a.

\begin{tabular}{rcccc} 
& \multicolumn{2}{c}{$\boldsymbol{S}$ Mosher's amide 1a } & \multicolumn{2}{c}{$\boldsymbol{R}$ Mosher's amide 1a } \\
\cline { 2 - 5 } & $\mathbf{4 - \boldsymbol { R }}$ & $\mathbf{4 - S}$ & $\mathbf{4 - \boldsymbol { R }}$ & $\mathbf{4 - S}$ \\
\cline { 2 - 5 }${ }^{1} \mathrm{H}$ - CMAE: & 0.12 & 0.13 & 0.08 & 0.22 \\
${ }^{13} \mathrm{C}$ - CMAE: & 3.49 & 3.56 & 3.52 & 3.57
\end{tabular}


Figure S8. Experimental (black solid) and sTDDFT calculated ECD spectra for 5- $R$ (black dashed) and $5-S$ (grey solid) indicating a 5- $R$ configuration in $\mathbf{1 a}$.

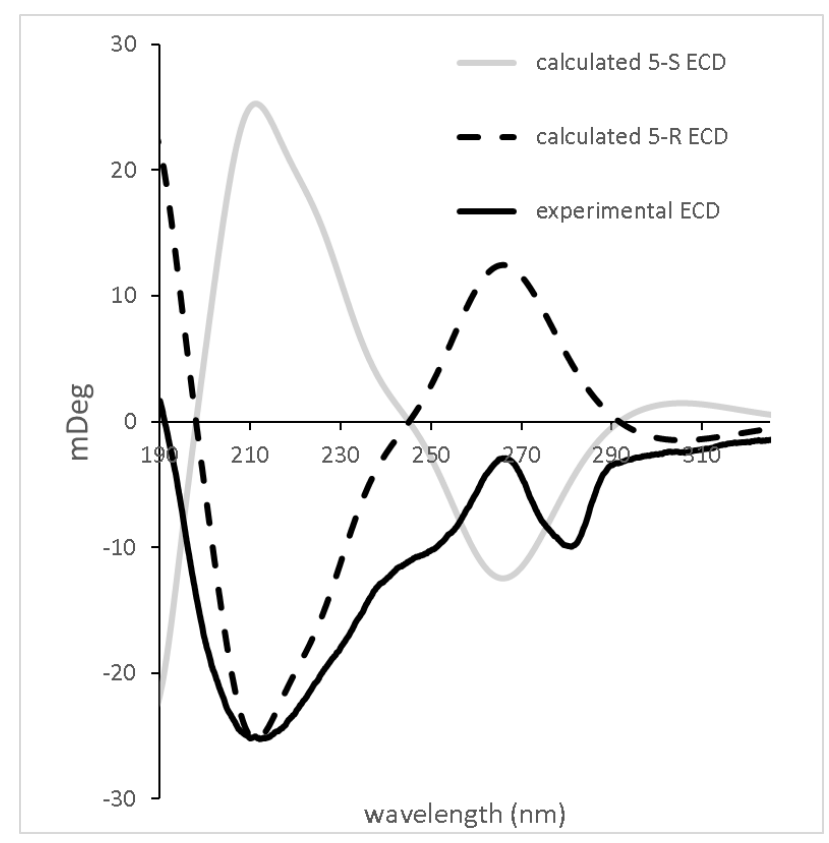

\section{ECD experimental details:}

ECD spectra of 1a were acquired on a Jasco J-1500 CD polararimeter at $25^{\circ} \mathrm{C}$ in acetonitrile at $0.025 \mathrm{c}$ from 190 to $500 \mathrm{~nm}$ scanned at $100 \mathrm{~nm} / \mathrm{min}$ with a $1 \mathrm{~nm}$ bandwidth with two acquisitions averaged and baseline corrected against an acetonitrile blank.

ECD data for 1a: $(0.025 \mathrm{c}$, acetonitrile) $212.1(-25.4), 238.8(-12.9), 265.9(-2.9), 281.0(-9.9)$

\section{Computational details:}

Conformers of 1a, (2S)-N-((4R)-4-(adamantan-1-yl)-4-(4-methoxyphenyl)-1-methyl-5-oxo-4,5dihydro-1H-imidazol-2-yl)-3,3,3-trifluoro-2-methoxy-2-phenylpropanamide, and (2R)-N-((4R)4-(adamantan-1-yl)-4-(4-methoxyphenyl)-1-methyl-5-oxo-4,5-dihydro-1H-imidazol-2-yl)-3,3,3trifluoro-2-methoxy-2-phenylpropanamide utilized for DFT and xtb4stda calculations were generated utilizing ForceGen 4.4 pquant conformational sampling. ${ }^{8}$ Gaussian '16 was utilized for all DFT calculations. ${ }^{9}$ Quantum mechanical DFT GIAO NMR chemical shift calculations were employed at the IEFPCM-mPW1PW91/6-311+G(2d,p)//M062X/6-311+G(2d,p) level for ${ }^{13} \mathrm{C}$ and 
WP04/aug-cc-pVDZ//B3LYP/6-31+G(d,p) level for ${ }^{1} \mathrm{H}$ shifts. ${ }^{10-11}$ Chemical shifts were Boltzmann averaged based on Gibb's Free Energies from frequence calculations at the $\omega B 97 x D /$ aug-cc-PVTZ level. The amide $\mathrm{NH}$ was excluded from CMAE ${ }^{1} \mathrm{H}$ comparisons of the Mosher's amides.

GFN2-xTB was utilized for geometry optimizations and Hessian calculations with GBSA solvation in acetonitrile for downstream use in computation of ECD spectra of 1a. ${ }^{12}$ sTDDFT at the GBSA- $\omega$ B97xD level was used to generate ECD spectra. ${ }^{13}$ Computed spectra were generated in SpecDis 1.71 and compared to experimental ECD spectra of 1a. ${ }^{14}$

\section{References:}

1. Otwinowski, Z. and Minor, W. (1997) Processing of X-ray diffraction data collected in oscillation modeMethods Enzymol. 276, 307-326

2. "Refinement of Macromolecular Structures by the Maximum-Likelihood method" G.N. Murshudov, A.A.Vagin and E.J.Dodson, (1997) in Acta Cryst. D53, 240-255.

3. M. D. Winn et al. Acta. Cryst. D67, 235-242 (2011) "Overview of the CCP4 suite and current developments"

4. Bricogne G., Blanc E., Brandl M., Flensburg C., Keller P., Paciorek W., Roversi P, Sharff A., Smart O.S., Vonrhein C., Womack T.O. (2017). BUSTER. Cambridge, United Kingdom: Global Phasing Ltd.

5. Emsley P., Lohkamp B., Scott W. G. \& Cowtan K. (2010) Features and Development of Coot. Acta Cryst. D66, 486-501.

6. Smart O. S., Womack T. O., Sharff A., Flensburg C., Keller P., Paciorek W., Vonrhein C. \& Bricogne G. (2011) grade. Cambridge, United Kingdom, Global Phasing Ltd.

7. The PyMOL Molecular Graphics System, Schrödinger, LLC

8. Jain, A. N.; Cleves, A. E.; Gao, Q.; Wang, X.; Liu, Y.; Sherer, E. C.; Reibarkh, M. Y., Complex macrocycle exploration: parallel, heuristic, and constraint-based conformer generation using ForceGen. Journal of Computer-Aided Molecular Design 2019, 33, 531558.

9. Frisch, M. J.; Trucks, G. W.; Schlegel, H. B.; Scuseria, G. E.; Robb, M. A.; Cheeseman, J. R.; Scalmani, G.; Barone, V.; Petersson, G. A.; Nakatsuji, H.; Li, X.; Caricato, M.; Marenich, A. V.; Bloino, J.; Janesko, B. G.; Gomperts, R.; Mennucci, B.; Hratchian, H. P.; Ortiz, J. V.; Izmaylov, A. F.; Sonnenberg, J. L.; Williams; Ding, F.; Lipparini, F.; Egidi, F.; Goings, J.; Peng, B.; Petrone, A.; Henderson, T.; Ranasinghe, D.; Zakrzewski, V. G.; Gao, J.; Rega, N.; Zheng, G.; Liang, W.; Hada, M.; Ehara, M.; Toyota, K.; Fukuda, R.; Hasegawa, J.; Ishida, M.; Nakajima, T.; Honda, Y.; Kitao, O.; Nakai, H.; Vreven, T.; Throssell, K.; Montgomery Jr., J. A.; Peralta, J. E.; Ogliaro, F.; Bearpark, M. J.; Heyd, J. J.; Brothers, E. N.; Kudin, K. N.; Staroverov, V. N.; Keith, T. A.; Kobayashi, R.; Normand, J.; Raghavachari, K.; Rendell, A. P.; Burant, J. C.; Iyengar, S. S.; Tomasi, J.; Cossi, M.; 
Millam, J. M.; Klene, M.; Adamo, C.; Cammi, R.; Ochterski, J. W.; Martin, R. L.; Morokuma, K.; Farkas, O.; Foresman, J. B.; Fox, D. J. Gaussian 16 Rev. B.01: Wallingford, CT, 2016.

10. Lodewyk, M. W.; Siebert, M. R.; Tantillo, D. J., Computational Prediction of 1H and 13C Chemical Shifts: A Useful Tool for Natural Product, Mechanistic, and Synthetic Organic Chemistry. Chemical Reviews 2012, 112, 1839-1862.

11. Wiitala, K. W.; Hoye, T. R.; Cramer, C. J., Hybrid Density Functional Methods Empirically Optimized for the Computation of $13 \mathrm{C}$ and $1 \mathrm{H}$ Chemical Shifts in Chloroform Solution. Journal of Chemical Theory and Computation 2006, 2, 1085-1092.

12. Bannwarth, C.; Ehlert, S.; Grimme, S., GFN2-xTB-An Accurate and Broadly Parametrized Self-Consistent Tight-Binding Quantum Chemical Method with Multipole Electrostatics and Density-Dependent Dispersion Contributions. Journal of Chemical Theory and Computation 2019, 15, 1652-1671.

13. Grimme, S.; Bannwarth, C., Ultra-fast computation of electronic spectra for large systems by tight-binding based simplified Tamm-Dancoff approximation (sTDA-xTB). The Journal of Chemical Physics 2016, 145, 054103.

14. Bruhn, T.; Schaumlöffel, A.; Hemberger, Y.; Bringmann, G., SpecDis: quantifying the comparison of calculated and experimental electronic circular dichroism spectra. Chirality 2013, 25, 243-9.

15. Castañar, L.; Sistaré, E.; Virgili, A.; Williamson, R. T.; Parella, T., Suppression of phase and amplitude $\mathrm{J}(\mathrm{HH})$ modulations in HSQC experiments. Magnetic Resonance in Chemistry 2015, 53, 115-119. 